\author{
UNIVERSIDADE DE SÃO PAULO \\ FACULDADE DE ODONTOLOGIA DE BAURU
}

FÁBIO DUARTE DA COSTA AZNAR

Análise da relação entre as condições de saúde bucal e a qualidade de vida em adolescentes com sobrepeso/obesidade e eutróficos em Bauru - SP 

FÁBIO DUARTE DA COSTA AZNAR

\section{Análise da relação entre as condições de saúde bucal e a qualidade de vida em adolescentes com sobrepeso/obesidade e eutróficos em Bauru - SP}

Tese apresentada a Faculdade de Odontologia de Bauru da Universidade de São Paulo para obtenção do título de Doutor em Ciências no Programa de Ciências Odontológicas Aplicadas, na área de concentração Odontologia em Saúde Coletiva.

Orientador: Prof. Dr. Arsenio Sales Peres

Versão Corrigida 


\begin{tabular}{|l|}
\hline \multirow{2}{*}{ Az52a } \\
Aznar, Fábio Duarte da Costa \\
Análise da relação entre as condições de saúde \\
bucal e a qualidade de vida em adolescentes com \\
sobrepeso/obesidade e eutróficos em Bauru - SP / \\
Fábio Duarte da Costa Aznar. - Bauru, 2015. \\
123 p. : il. ; 31cm. \\
Tese (Doutorado) - Faculdade de Odontologia \\
de Bauru. Universidade de São Paulo \\
Orientador: Prof. Dr. Arsenio Sales Peres \\
\end{tabular}

Nota: A versão original desta tese encontra-se disponível no Serviço de Biblioteca e Documentação da Faculdade de Odontologia de Bauru $\mathrm{FOB} / \mathrm{USP}$

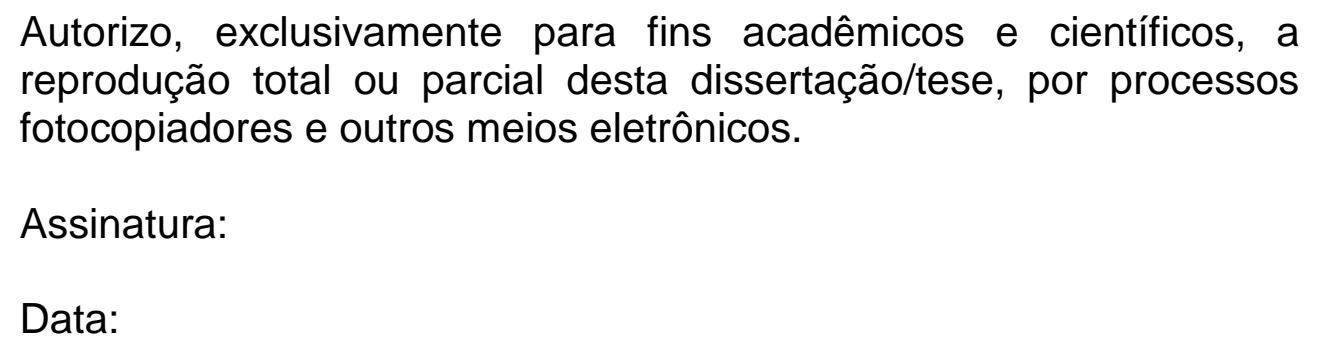
reprodução total ou parcial desta dissertação/tese, por processos fotocopiadores e outros meios eletrônicos.

Assinatura:

Data:

Comitê de Ética da FOB-USP

CAAE: 06395012.8 .0000 .5417

Data: $01 / 10 / 2012$ 




\section{Dedicatória}

À Deus, pela vida.

Aos meus pais João Carlos Aznar e Clóris Duarte da Costa Aznar, pelos exemplos de caráter; e pela educação, carinho e compreensão que permitiram alcançar meus objetivos com humildade e respeito ao próximo.

Aos meus irmãos Fabiano Duarte da Costa Aznar e Fabíola Duarte da Costa Aznar, pelo eterno amor e companheirismo.

Á minha noiva, futura esposa, amiga, colega de doutorado e razão da minha vida Adriana Rodrigues de Freitas, pela imensurável ajuda na confecção desta tese e por tudo o que fez e faz por mim. Minha eterna gratidão. 



\section{Agradecimentos}

Ao professor, orientador e amigo Prof. Dr. Arsenio Sales Peres, que durante a confecção desta Tese esteve ao meu lado como orientador e amigo. Mesmo perante numerosos compromissos e afazeres, estendeu a mão amiga e calorosa para concretização dessa jornada. Meu reconhecimento e gratidão pelo incansável incentivo para meu crescimento profissional e pessoal, sem os quais não poderia atingir meus objetivos dentro da Odontologia. Foi de inestimável valor para a construção e manutenção de meu futuro, não só profissional, como também pessoal.

Obrigado pela amizade, orientação, paciência e confiança; e por ter feito de nossa amizade algo fraternal, fazendo de sua família a minha também.

"Ser honesto não te trará muitos amigos. Mas com certeza lhe trará os amigos certos" (John Lennon).

Tenha certeza de que um dia irei retribuí-lo por tudo, amigo.

A professora Profa. Dra. Sílvia Helena de Carvalho Sales Peres, exemplo maior de competência e profissionalismo.

Obrigado pela amizade, confiança e aconselhamentos fundamentais para esta tese; e pelo incentivo à vida acadêmica, ainda na graduação. Exemplo a ser seguido. 

Aos professores Prof. Dr. José Roberto de Magalhães Bastos e Prof. Dr. Arnaldo Pinzan, pelas contribuições diretas e colocações fundamentais para a finalização deste trabalho.

Aos professores da Disciplina de Saúde Coletiva, do Departamento de Odontopediatria, Ortodontia e Saúde Coletiva da Faculdade de Odontologia de Bauru (USP): Prof. Dr. Eliel Soares Orenha, Prof. Dr. Heitor Marques Honório, Prof. Dr. José Roberto Pereira Lauris, Profa. Dra. Nilce Emy Tomita, Prof. Dr. Roosevelt da Silva Bastos e Profa. Dra. Magali de Lourdes Caldana, fundamentais na minha formação. Obrigado por sempre estarem solícitos.

A todos os colegas pós-graduandos da Disciplina de Saúde Coletiva, do Departamento de Odontopediatria, Ortodontia e Saúde Coletiva da Faculdade de Odontologia de Bauru (USP); pessoas fundamentais nesta caminhada, com certeza amigos para a vida toda. Em especial aos colegas Adriana Freitas, Marcos Capelari, Mauricio Spin, Bruno Calvazara, Silvia Alvarenga, Marli Monteiro, Nathalia Pereira, Ana Paula Chedid, e Ênio Trujillo.

Aos funcionários da Disciplina de Saúde Coletiva, do Departamento de Odontopediatria, Ortodontia e Saúde Coletiva da Faculdade de Odontologia de Bauru (USP); Rosa, Sílvia e Marta, pela atenção e disponibilidade em me ajudar.

A Universidade de São Paulo, por meio do reitor Prof. Dr. Marco Antonio Zago; e a Faculdade de Odontologia de Bauru, por meio de sua diretora Profa. Dra. Maria Aparecida de Andrade Moreira Machado, e do presidente da comissão de Pós-Graduação Prof. Dr. Guilherme dos Reis Pereira Janson.

A Coordenação de Aperfeiçoamento de Pessoal de Nível Superior (CAPES), pelo apoio e fomento durante a elaboração desta tese. 

A todos os demais professores, alunos graduandos e pós-graduandos, e funcionários da Faculdade de Odontologia de Bauru (USP).

A Prefeitura Municipal de Bauru, em nome do Prefeito Rodrigo Antônio de Agostinho Mendonça, e a Secretaria Municipal de Educação de Bauru, em nome da Secretária Profa. Vera Mariza Regino Casério.

As diretoras, alunos e funcionários das escolas municipais de ensino fundamental de Bauru: EMEF Ivan Engler de Almeida, EMEF Cônego Aníbal Difrância, EMEF Santa Maria, EMEF Nacilda de Campos e NER Lydya Alexandrina, imprescindíveis na realização desta tese. Obrigado pela atenção, paciência e solicitude.

A todos meus alunos e ex-alunos, que tive a oportunidade, felicidade e responsabilidade de poder compartilhar um pouco de conhecimento. 



\section{"Cada sonbo que você deixa para trás,}

é um pedaço do seu futuro que deixa de existir." Sterve Jobs 



\section{RESUMO}

A obesidade infantil vem ganhando destaque em todo o mundo, uma vez que as crianças com sobrepeso apresentam uma tendência de se tornarem adultas com excesso de peso, ocasionando doenças graves, diminuição da expectativa de vida e insalubridade emocional. A mudança de hábitos que tem levado à substituição dos alimentos ricos em fibras e nutrientes por alimentos industrializados ricos em gorduras e carboidratos facilita o surgimento de problemas odontológicos, mesmo com a exposição a fatores de proteção. O objetivo deste estudo foi analisar a relação entre as condições de saúde bucal e a qualidade de vida de adolescentes com sobrepeso/obesidade e eutróficos em Bauru - São Paulo. A amostra foi constituída por 153 adolescentes aos 12 anos, ambos os gêneros, matriculados na rede de ensino municipal, divididos em dois grupos G1 - Sobrepeso/Obesidade $(n=65)$ e $G 2$ - Eutróficos ( $n=88)$. A avaliação antropométrica foi realizada por meio do Índice de Massa Corpórea (IMC). Os exames bucais foram realizados por 2 examinadores calibrados (Kappa>0,76), avaliando-se cárie dentária (CPOD), fluorose (Índices de Dean e de Fluorose Comunitária), condições periodontais (IPC), desgaste dentário (IDD), má oclusão (DAI) e fluxo salivar ( $\mathrm{ml} / \mathrm{min}$ ). O questionário CHILD-OIDP foi aplicado. Para a análise estatística dos dados aplicou-se o teste de normalidade e homogeneidade, empregando-se teste "t" de Student, Mann-Whitney, Qui-Quadrado, Odds Ratio e Coeficiente Linear de Correlação de Pearson $(p<0,05)$. A média de IMC encontrado foi 22,98 $\pm 3,39$ (masculino) e 23,78 $\pm 3,23$ (feminino) em

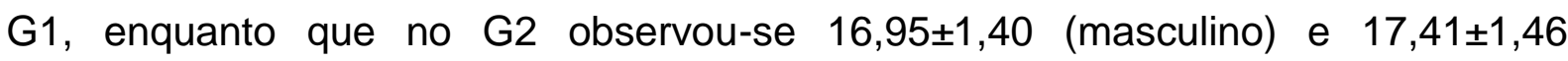

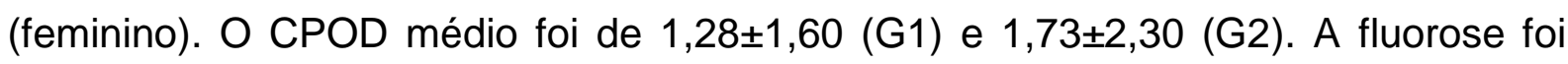
identificada em 23,08\% (G1) e 14,77\% (G2). As alterações periodontais foram mais prevalentes em G2 $(65,91 \%)$ do que G1 $(52,31 \%)$, com a presença de sangramento gengival em 47,69\% e 47,73\% e de cálculo em 29,23\% e 44,32\% (G1 e G2, respectivamente). Todos os adolescentes apresentaram algum grau de desgaste dentário, sendo a face incisal/oclusal a mais acometida (G1 97,88\%; G2 97,02\%). A

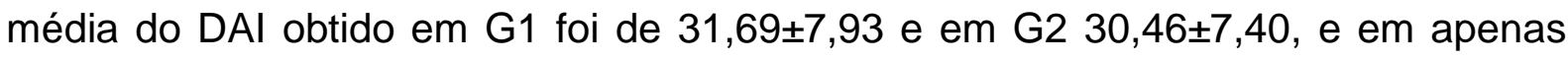
29,23\% (G1) e 22,73\% (G2) houve normalidade/oclusopatia leve. Em relação ao fluxo salivar, independente do grupo, a hiposalivação foi a mais frequente $(49,23 \%$ G1 e 48,86\% - G2). Os escores médios obtidos no questionário CHILD-OIDP foram

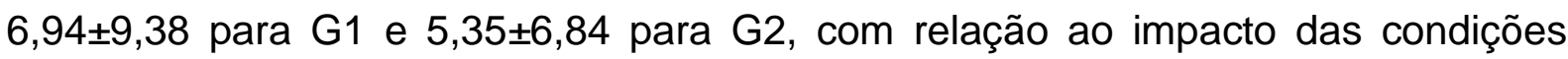



bucais nas atividades diárias em G1 observou-se prevalência moderada em comer, estado emocional e sorrir; e impacto moderado em sorrir e pequeno em comer e higienização bucal em G2. Não foram observadas associações entre o IMC e cárie dentária, fluorose, condições periodontais e má oclusão, apenas quanto à severidade do desgaste dentário $(p=0,029)$. Observou-se correlação negativa entre o fluxo salivar e a qualidade de vida nos adolescentes com sobrepeso/obesidade. É fundamental uma abordagem estratégica e multidisciplinar da obesidade e dos fatores de risco que predispõe para esta condição, uma vez que estes podem resultar em agravos a saúde bucal dos adolescentes.

Palavras-chave: Adolescente. Cárie dentária. Doenças periodontais. Má oclusão. Obesidade. Qualidade de vida. Xerostomia. 



\section{ABSTRACT \\ Analysis of the relationship between oral health status and quality of life in overweight $I$ obese and eutrophic adolescents in Bauru - SP}

Childhood obesity has been gaining attention throughout the world, since overweight children have a tendency to become overweight adults, causing severe disease, decreased on life expectancy and emotional unhealthiness. The change in habits that have led to the replacement of fiber-rich foods and nutrients for processed foods rich in fats and carbohydrates facilitates the emergence of dental problems, even with exposure to the protective factors. The objective of this study was to analyze the relationship between oral health status and quality of life in overweight / obese and eutrophic adolescents in Bauru - São Paulo. The sample consisted of 153 adolescents age 12, both genders, enrolled in the municipal school system, divided into two groups G1 - Overweight / obesity $(n=65)$ and $G 2$ - normal weight $(n=88)$. The anthropometric assessment was performed using the Body Mass Index (BMI). Oral examinations were performed by two calibrated examiners (kappa>0.76), evaluating dental caries (DMFT), fluorosis (Dean and Community fluorosis Indexes), periodontal conditions (CPI), dental wear (DWI), malocclusion (DAI) and salivary flow (ml / min). The CHILD-OIDP questionnaire was applied. Data statistics analysis applied the normality and homogeneity test, using then Student t-test, Mann-Whitney, Chi-square, Odds Ratio and Linear Coefficient of Correlation of Pearson $(p<0.05)$. The mean BMI was $22.98 \pm 3.39$ (male) and $23.78 \pm 3.23$ (female) in G1, while in G2 there was $16.95 \pm 1.40$ (male) and 17, $41 \pm 1.46$ (female). The average DMFT was $1.28 \pm 1.60(\mathrm{G} 1)$ and $1.73 \pm 2.30(\mathrm{G} 2)$. Periodontal changes were more prevalent in G2 (65.91\%) than G1 (52.31\%), with presence of gingival bleeding in $47.69 \%$ and $47.73 \%$ and calculus in 29.23\% and 44 32\% (G1 and $\mathrm{G} 2$ respectively). All adolescents had some degree of tooth wear, and the incisal / occlusal surface was the most affected (97.88\% G1; 97.02\% G2). The average DAl obtained in G1 was $31.69 \pm 7.93$ and $30.46 \pm 7.40$ in G2, and only $29.23 \%$ (G1) and $22.73 \%$ (G2) was normal / mild malocclusion. Relative to the salivary flow, regardless of group, hyposalivation was the most frequent (49.23\% - 48.86\% and G1 - G2). The average scores obtained in CHILD-OIDP questionnaire were 6.94 $\pm 9.38 \mathrm{G} 1$ and $5.35 \pm 6.84$ G2, regarding the impact of oral conditions in daily activities in G1 there was 

moderate prevalence on eating, emotional state and smiling; and a moderate impact on smiling and low impact on eating and cleaning mouth in G2. No associations were observed between BMI and dental caries, fluorosis, periodontal conditions and malocclusion, just about the severity of tooth wear $(P=0.029)$. There was a negative correlation between salivary flow and the quality of life in adolescents with overweight I obesity. It is crucial a strategic and multidisciplinary approach for obesity and the risk factors that predispose to this condition, since these can result in injuries to adolescents' oral health.

Keywords: Adolescent. Dental caries. Periodontal diseases. Malocclusion. Obesity. Quality of life. Xerostomia. 



\section{LISTA DE ILUSTRAÇÕES}

\section{- FIGURAS}

Figura 1 - Localização do Município de Bauru - Estado de São Paulo.

Figura 2 - Aferição da altura e do peso dos adolescentes para a antropometria 64

Figura 3 - Sonda periodontal preconizada pela OMS (WHO, 1997). 64

Figura 4 - Sequência realizada para aferição do volume da saliva ( $\mathrm{ml} / \mathrm{min}) \ldots . .71$

\section{- QUADROS}

Quadro 1 - Códigos e condições empregados nos índices ceod e CPOD........

Quadro 2 - Códigos e condições empregados para necessidade de tratamento.

Quadro 3 - Códigos, classificação e critérios do Índice de Dean (DEAN, 1934)

Quadro 4 - Índices, classificação e interpretação do índice de fluorose dentária da comunidade (DEAN, 1934)

Quadro 5 - Códigos, condições e critérios do IPC (BRASIL, 2011; WHO,1997)

Quadro 6 - Códigos, condições e critérios do IDD (Sales-Peres et al., 2008).

Quadro 7 - Dimensões, situação e códigos/critério do DAI (WHO,1997) adaptado.

Quadro 8 - Classificação da má oclusão com relação à severidade.

Quadro 9 - Parâmetros para a avaliação do fluxo salivar. 

- GRÁFICOS

Gráfico 1 - Porcentagem da amostra com SPO e EUT............................. 77

Gráfico 2 - Concentração por gênero nos grupos SPO e EUT....................... 77

Gráfico 3 - Porcentagem de adolescentes livres de cárie observada nos dois

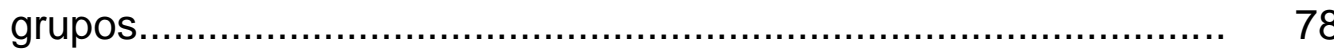

Gráfico 4 - Porcentagem de adolescentes com fluorose observado nos dois grupos

Gráfico 5 - Frequência em ambos os grupos, em função da severidade da

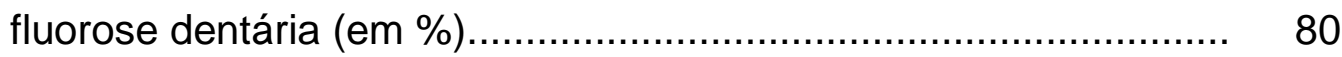

Gráfico 6 - Índice de fluorose comunitário observado nos dois grupos............ 81

Gráfico 7 - Porcentagem de adolescente que apresentaram alterações

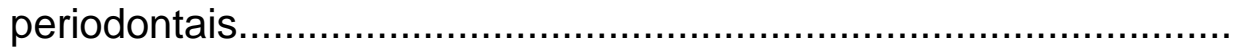

Gráfico 8 - Prevalência de desgaste dentário por grupos de dentes nos adolescentes com SPO (G1) e EUT (G2).............................. 83

Gráfico 9 - Frequência em função da severidade da má oclusão dentária (em \%) entre os grupos SPO (G1) e EUT (G2)....

Gráfico 10 - Médias do fluxo salivar (em $\mathrm{ml} / \mathrm{min}$ ) observadas nos dois grupos

Gráfico 11 - Frequência em ambos os grupos em função da condição de salivação (em \%). 



\section{LISTA DE TABELAS}

Tabela 1 - Frequência absoluta dos TCLEs distribuídos, e frequência absoluta e relativa de adolescentes examinados nas escolas municipais,

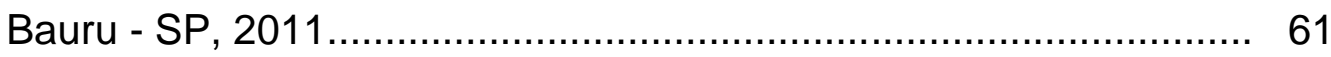

Tabela 2 - Distribuição da cárie dentária nos adolescentes com SPO (G1) e

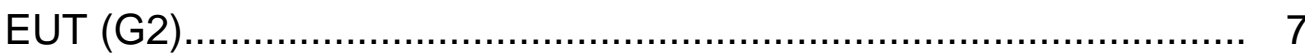

Tabela 3 - Índice CPOD e comparação entre os grupos SPO (G1) e EUT (G2)

Tabela 4 - Associação entre cárie dentária e IMC nos adolescentes com SPO (G1) e EUT (G2).

Tabela 5 - Associação entre a Fluorose dentária e IMC nos adolescentes com SPO (G1) e EUT (G2).

Tabela 6 - Presença de sangramento gengival e cálculo dentário nos adolescentes com SPO (G1) e EUT (G2).

Tabela 7 - Associação entre condições periodontais e IMC nos adolescentes com SPO (G1) e EUT (G2)

Tabela 8 - Prevalência de desgaste dentário por faces nos adolescentes com SPO (G1) e EUT (G2).

Tabela 9 - Severidade do desgaste dentário por grupos de dentes nos adolescentes com SPO (G1) e EUT (G2).

Tabela 10 - Associação entre desgaste dentário e IMC nos adolescentes com SPO (G1) e EUT (G2).

Tabela 11 - Índice DAl e comparação entre os grupos SPO (G1) e EUT (G2).... 85

Tabela 12 - Associação entre DAI e IMC nos adolescentes com SPO (G1) e EUT (G2)

Tabela 13 - Fluxo salivar (ml/min) e comparação entre os grupos SPO (G1) e EUT (G2).

Tabela 14 - Associação entre Fluxo salivar e IMC nos adolescentes com SPO (G1) e EUT (G2)

Tabela 15 - Condições bucais percebidas pelos adolescentes com SPO (G1) e EUT (G2). 

Tabela 16 - Escores médios do OIDP-CH obtidos pelos adolescentes com SPO (G1) e EUT (G2).

Tabela 17 - Impacto das condições bucais percebidas nas atividades diárias dos adolescentes com SPO (G1) e EUT (G2).

Tabela 18 - Associação entre o impacto nas atividades diárias e o IMC nos adolescentes com SPO (G1) e EUT (G2)...

Tabela 19 - Correlação Linear de Pearson entre CHILD-OIDP e condições bucais entre os adolescentes com SPO (G1) e EUT (G2) 



\section{LISTA DE ABREVIATURAS E SIGLAS}

$\begin{array}{ll}\text { CEP } & \text { Comitê de Ética em Pesquisa } \\ \text { CHILD-OIDP } & \text { Oral Impacts on Daily Performances for children } \\ \text { CPOD } & \text { Cariados, Perdidos e Obturados (Restaurados) } \\ \text { DAI } & \text { Dental Aesthetic Index } \\ \text { DNA } & \text { Deoxyribonucleic Acid } \\ \text { EUT } & \text { Eutróficos } \\ \text { FOB-USP } & \text { Faculdade de Odontologia de Bauru, Universidade de São Paulo } \\ \text { G1 } & \text { Grupo 1 } \\ \text { G2 } & \text { Grupo 2 } \\ \text { IBGE } & \text { Instituto Brasileiro de Geografia e Estatística } \\ \text { IDD } & \text { Índice de Desgaste Dentário } \\ \text { IMC } & \text { Índice de Massa Corpórea } \\ \text { IPC } & \text { Índice Periodontal Comunitário } \\ \text { Kg } & \text { Quilograma } \\ \text { m } & \text { Metro } \\ \text { min } & \text { Minuto } \\ \text { ml } & \text { Mililitro(s) } \\ \text { mm } & \text { Milímetro(s) } \\ \text { OIDP } & \text { Oral Impacts on Daily Performances } \\ \text { OMS } & \text { Organização Mundial de Saúde } \\ \text { OR } & \text { Odds Ratio } \\ \text { pH } & \text { Potencial Hidrogeniônico } \\ \text { POF } & \text { Pesquisa de Orçamento Familiar } \\ \text { SIC } & \text { Índice significativo de cárie } \\ \text { SP } & \text { São Paulo } \\ \text { SPO } & \text { Tobrepeso/Obesidade } \\ \text { TCLE } & \text { World Health Organization } \\ \text { WHO } & \\ & \end{array}$





\section{SUMÁRIO}

1 INTRODUÇÃO $\quad 39$

2 REVISÃO DE LITERATURA 43

2.1 SOBREPESO/OBESIDADE 43

2.1.1 Sobrepeso/Obesidade em adolescentes 43

2.2 AVALIAÇÃO ANTROPOMÉTRICA 44

2.3 SOBREPESO/OBESIDADE E SAÚDE BUCAL 45

2.3.1 Condições de saúde bucal em adolescentes com sobrepeso/obesidade 45

2.4 QUALIDADE DE VIDA E SAÚDE BUCAL EM ADOLESCENTES COM SOBREPESO/OBESIDADE 50

3 PROPOSIÇÃO

3.1 OBJETIVO GERAL 55

3.2 OBJETIVOS ESPECÍFICOS 55

4 MATERIAL E MÉTODOS 59

4.1 ASPECTOS ÉTICOS 59

4.2 OPÇÃO METODOLÓGICA 59

4.3 CRITÉRIOS DE INCLUSÃO E EXCLUSÃO 59

4.4 CÁLCULO DA AMOSTRA 59

4.5 COMPOSIÇÃO DA AMOSTRA 60

4.6 ETAPAS DO ESTUDO 61

4.6.1 Calibração dos examinadores 61

4.6.2 Apresentação do projeto e distribuição dos termos de consentimento livre e esclarecido (TCLE) 62

4.6.3 Avaliação epidemiológica 63

4.6.3.1 Análise antropométrica 63

4.6.3.2 Exames clínicos $\quad 64$

4.6.3.3 Aplicação de questionário 72

$\begin{array}{lll}\text { 4.6.4 Analise estatística } & 73\end{array}$

5 RESULTADOS $\quad 77$

5.1 CARACTERIZAÇÃO DA AMOSTRA

5.2 CONDIÇÕES DE SAÚDE BUCAL 78 

5.2.1 Cárie dentária 78

$\begin{array}{lll}5.2 .2 & \text { Fluorose dentária } & 79\end{array}$

5.2.3 Condição periodontal 81

5.2.4 Desgaste dentário 82

5.2.5 Má oclusão dentária 84

5.2.6 Fluxo salivar 85

5.3 QUESTIONÁRIO SOBRE O IMPACTO DAS ATIVIDADES DIÁRIAS NA QUALIDADE DE VIDA 86

6 DISCUSSÃO 93

6.1 ANÁLISE ANTROPOMÉTRICA 93

6.2 CONDIÇÃO BUCAL 94

6.3 QUALIDADE DE VIDA 99

7 CONCLUSÕES 103

$\begin{array}{ll}\text { REFERÊNCIAS } & 107\end{array}$

$\begin{array}{lr}\text { ANEXOS } & 119\end{array}$ 



\section{Introdução}



1 INTRODUÇÃO

O conhecimento da situação nutricional da população é essencial para aferir a evolução das condições de saúde e de vida, considerando seu caráter multicausal, relacionado ao grau de atendimento das necessidades básicas (SALESPERES et al., 2010).

Observa-se que o perfil nutricional das populações tem sofrido modificações, com significativo aumento da obesidade tanto em países desenvolvidos quanto em países em desenvolvimento, sendo considerada como "a epidemia do século XXI"; devendo-se ressaltar que esta condição apresenta envolvimentos psicológicos, bioquímicos, metabólicos, alterações anatômicas e sociais (TAUBES, 1998).

A obesidade atualmente representa um considerável problema de saúde pública, pois além de ter forte impacto na morbidade, um peso corporal mais elevado está associado a um maior risco de diabetes tipo 2, e pode ser um fator de risco para doenças cardiovasculares, hipertensão, asma, artrite e outros problemas de saúde geral (SINHA et al., 2002; MARCENES et al., 2003).

Recentemente, o tema obesidade infantil vem ganhando grande destaque, tanto em países desenvolvidos como em desenvolvimento, pois as crianças que apresentaram sobrepeso poderão tornar-se adultas com excesso de peso (GUO \& CHUMLEA, 1999). Consequentemente, quando se apresenta precocemente, a mesma pode levar a doenças graves, diminuição da expectativa de vida e resultar em insalubridade emocional (DIETZ \& ROBINSON, 1998). No Brasil, segundo a Pesquisa de Orçamento Familiar (POF) realizada entre 2008/2009 pelo Instituto Brasileiro de Geografia e Estatística (IBGE), o índice de jovens de 10 a 19 anos com excesso de peso passou de 3,7\%, em 1970, para 21,7\%, acima do recomendado pela Organização Mundial da Saúde (WHO, 2015) e pelo Ministério da Saúde em 2009 (BRASIL, 2010).

Além disso, este tema demonstra-se de grande interesse para a Odontologia, visto que a mudança de hábitos alimentares dos brasileiros, que tem levado à substituição dos alimentos ricos em fibras e nutrientes por alimentos industrializados ricos em gorduras e carboidratos, facilita o surgimento de problemas odontológicos, mesmo com a exposição a fatores de proteção amplamente difundidos (TRAEBERT et al., 2001). Evidencia-se que o aumento de peso 
predispõe o indivíduo a problemas bucais tais como cárie dentária, periodontite e consequente perda dentária; além de erosão, hipersensibilidade dentária e xerostomia (BARRON et al., 2003; HELING et al., 2006; MATHUS-VLIEGEN et al., 2007; TOUGER-DECKER et al., 2007; KELISHADI et al., 2010).

Tendo em vista o aumento na prevalência da obesidade, e pelo fato de haver evidências da correlação entre o ganho de peso e o comprometimento da condição bucal, é fundamental abordar este tema mais incessantemente, pois a saúde bucal constitui parte da saúde geral e é elemento essencial para a qualidade de vida (TESCH et al., 2007). Além disso, o conhecimento dos fatores de risco permite a adequação dos cuidados de saúde bucal e reorientação de gastos com prevenção, respeitando-se assim o princípio da equidade, visto que tais fatores têm sido discutidos com frequência, incluindo fatores sociais e comportamentais (PERES et al., 2000). Ou seja: O conhecimento da distribuição e frequência de doenças proporciona melhores condições de planejamento estratégico levando para a população assistência à saúde, acesso aos métodos preventivos e promoção de saúde.

Os estudos de base populacional são ferramentas necessárias para nortear o planejamento e a tomada de decisões em políticas públicas de saúde. Quando se utiliza esta forma de estudo na saúde bucal, historicamente o critério de avaliação sempre foi baseado em critérios clínicos, o que não permite a determinação do real impacto da mesma na vida dos indivíduos. Frente a esta necessidade de determinar a repercussão integral de possíveis alterações bucais, desenvolveu-se instrumentos de avaliação da qualidade de vida em relação à condição bucal, o que vem sendo utilizado com uma frequência cada vez maior em pesquisas (JOKOVIC et al., 2002).

Este trabalho tem como justificativa a falta de consenso da literatura científica, no que tange à dados epidemiológicos referentes ao impacto da obesidade na saúde bucal e na qualidade de vida de adolescentes. 


\section{Rezisão de Literatura}





\section{REVISÃO DE LITERATURA}

\subsection{SOBREPESO/OBESIDADE}

A obesidade é uma doença universal de prevalência crescente e que vem adquirindo proporções epidêmicas, sendo um dos principais problemas de saúde pública da sociedade moderna (GARRIDO JUNIOR et al., 2006). Em 2004, Buchwald \& Willians estimaram que 1,7 bilhões de pessoas em todo mundo apresentavam sobrepeso e obesidade, atribuindo 2,5 milhões de mortes por anos à obesidade.

Atualmente, há uma tendência de ascensão das prevalências de sobrepeso e de obesidade, tanto nos países desenvolvidos quanto naqueles em desenvolvimento. Aspectos singulares da transição nutricional ocorrida neste século são encontrados em cada país e região do mundo, contudo são elementos comuns: o declínio no dispêndio energético, uma dieta rica em gordura (particularmente as de origem animal), açúcar e alimentos refinados, porém reduzida em carboidratos complexos e fibras (VASCONCELOS \& SILVA, 2003).

Algumas das doenças crônicas e não infecciosas na sociedade moderna estão associadas à obesidade. Dentre estas comorbidades, cita-se o diabetes mellitus tipo 2, hipertensão arterial, dislipidemia, arteriosclerose, artrite, síndrome de apneia do sono, refluxo gastresofágico, infertilidade e incontinência urinária em mulheres, disfunções endócrinas, disfunção da vesícula biliar, problemas pulmonares, alguns tipos de câncer, falta de habilidade para atividades diárias, problemas psicossociais e econômicos (FRANCISCHI et al., 2000; SINHA et al., 2002; MARCENES et al., 2003).

\subsubsection{Sobrepeso/Obesidade em adolescentes}

O sobrepeso e obesidade, na infância e adolescência, está sendo considerada pela Organização Mundial de Saúde (OMS) um problema de saúde pública, quer pelas consequências fisiológicas, quer pelos prejuízos cognitivos e comportamentais e também pelos seus efeitos deletérios à qualidade de vida dos jovens (LAITINEN et al., 2001). Muitos desses efeitos negativos persistem na idade 
adulta (KIESS et al., 2001), tendo-se talvez, como principal exemplo, o aumento do riscos de se desenvolver futuramente doenças crônicas (GUO \& CHUMLEA, 1999).

A tendência destas condições envolver populações cada vez mais jovens sinaliza para um prognóstico ainda mais sombrio, pois se sabe que a precocidade da instalação do problema associa-se, fortemente, à persistência desta condição clínica na vida adulta, projetando-se assim uma geração futura com percentuais ainda mais de obesos (RIBEIRO JUNIOR, 2007).

Sendo assim, deve-se dar uma especial atenção a presença de sobrepeso e obesidade em adolescentes, que no Brasil, segundo o IBGE em 2010, apresentava uma incidência em jovens de 21,7\%, acima do recomendado pela OMS. Portanto é fundamental precocemente buscar reverter esta condição, visto que a mesma é difícil de ser tratada em função de sua etiologia multifatorial, que resulta da complexa interação entre fatores ambientais, genéticos e psicológicos; e cujos programas de tratamento devem envolver o controle destes três fatores (MERTENS \& VAN GAAL, 2000).

\subsection{AVALIAÇÃO ANTROPOMÉTRICA}

Dentre as várias formas de mensuração da obesidade, o índice de massa corpórea (IMC) tornou-se padrão referencial para essa avaliação, tanto em âmbito individual como populacional, pois o mesmo apresenta praticidade, simplicidade e elevado grau de confiabilidade na indicação da gordura corporal. Este índice é obtido dividindo-se o peso da pessoa, expresso em quilos, pela altura, expresso em metros, elevada ao quadrado (LIMA \& SAMPAIO, 2007; SANTO \& CECCONELLO, 2008).

O IMC, embora apresente em adolescentes importante variação com a idade e maturidade sexual, tem sido considerado como bom indicador de obesidade em adolescentes (SALES-PERES et al., 2010). Sendo assim, na idade específica de 12 anos, segundo a OMS é fundamental adequar estas variações em relação à idade, gênero e relação peso/altura, empregando-se este índice de forma mais correta (WHO, 1997). 
2.3 SOBREPESO/OBESIDADE E SAÚDE BUCAL

A obesidade pode provocar o aparecimento de outras doenças que agravam o estado de saúde do paciente, trazendo, assim, prejuízos à saúde sistêmica, com possibilidade de comprometer a saúde bucal (TRAEBERT et al., 2004). A literatura evidencia que o aumento de peso predispõe o indivíduo a problemas bucais tais como cárie dentária, periodontite e consequente perda dentária; além de erosão, hipersensibilidade dentária e xerostomia (BARRON et al., 2003; HELING et al., 2006; MATHUS-VLIEGEN et al., 2007; TOUGER-DECKER et al., 2007; KELISHADI et al., 2010).

\subsubsection{Condições de saúde bucal em adolescentes com sobrepeso/obesidade}

A obesidade, as doenças dela decorrentes e também a cárie dentária tem no hábito alimentar um importante componente etiológico comum (SALES-PERES et al., 2010). Apesar da natureza multifatorial do processo carioso ser relevante e não poder ser desconsiderado, é consenso que a frequência e a quantidade total de ingestão de carboidratos fermentáveis estão relacionadas com a incidência da cárie dentária (MOYNIHAN et al., 2005). Portanto, os hábitos alimentares relacionados à obesidade podem também determinar maior prevalência de cárie dentária (SALESPERES et al., 2010). Entretanto, os estudos epidemiológicos que investigaram a relação entre a cárie dental e sobrepeso/obesidade em adolescentes encontraram resultados conflitantes (ALVES et al., 2013).

Moreira, em 2003, objetivou verificar a associação entre cárie dentária e obesidade em 3330 adolescentes de 12 a 15 anos de escolas públicas e privadas, na cidade de João Pessoa - PB, comparando as médias de CPOD e a prevalência de cárie entre os obesos e eutróficos nos dois tipos de escolas. Os autores observaram que não houve relação entre cárie dental e obesidade sendo, entretanto, superiores entre os adolescentes das escolas públicas. Estudo semelhante conduzido na Índia por Shailee et al., em 2012, avaliaram a associação entre o peso e a cárie dentária em 1011 adolescentes de 12 e 15 anos em escolas publicas e privadas, na cidade de Shimla, utilizando critérios da OMS. Observou-se uma alta porcentagem de crianças com baixo peso, sendo que esta condição 
apresentava-se com um CPOD maior quando comparada com crianças com sobrepeso, além de que as escolas públicas possuíam maior índices de cárie dentária quando comparada com as escolas privadas. Para os autores, as condições socioeconômicas e o desconhecimento de higiene bucal por parte das crianças contribuem para os resultados encontrados. Resultados parecidos foram observados por Goodson et al., em 2013, avaliando a relação entre a condição antropométrica e a cárie dental em adolescente do Kuwait com média de idade de 11,36 anos. Os autores observaram que a porcentagem de adolescentes com dentes cariados ou restaurados variou inversamente com a classificação antropométrica: Adolescentes com baixo peso $(15,61 \%)$, eutróficos $(13,03 \%)$, sobrepeso $(9,73 \%)$, e obesas (7,87\%); apresentando diferenças estatísticamente significantes.

Alves et al., em 2013, avaliaram o status do peso e a associação com a cárie dentária em adolescentes de 12 anos de escolas públicas e privadas na cidade de Porto Alegre - RS, e também concluíram que as condições de sobrepeso e obesidade não aumentaram o risco à cárie dentária na população avaliada. Freitas et al., em 2014, em estudo realizado na cidade de Dois Córregos, estado de São Paulo, observaram que adolescentes aos 12 anos de idade com sobrepeso/obesidade apresentavam-se livres de cárie (42.57\%) em uma maior prevalência quando comparados com adolescentes Eutróficos (28.71\%), acompanhando o índice CPOD esta característica na comparação entre os dois grupos: 1.67 (sobrepeso/obesidade) e 2.12 (eutróficos).

Entretanto, Tambelini et al., 2010, investigaram a prevalência da cárie dentária e sua associação com fatores sociodemográficos e o excesso de peso em 424 adolescentes entre 15 e 19 anos de idade na cidade de Londrina - PR. Os autores observaram que apesar da ausência de associação estatística, a maior severidade de cárie foi registrada entre adolescentes com sobrepeso e a menor, entre os obesos; sendo que os indicadores sociodemográficos exerceram importante influência na prevalência de cárie na população estudada.

Com relação à condição periodontal, os estudos tem demonstrado associação entre o aumento de peso e a prevalência de alterações periodontais em adultos, sendo porém escassos aqueles que se propuseram a abordar este tema em adolescentes (MODÉER et al., 2011). 
Modéer et al., em 2011, testaram a hipótese de obesidade na adolescência estar associada com doença periodontal ou de indicadores de risco, analisando-se 104 adolescentes eutróficos e obesos com idade média de 14,5 anos, residentes em Estocolmo, Suécia. Os autores observaram que adolescentes obesos exibiram maior presença de inflamação gengival e bolsas periodontais em comparação com os indivíduos Eutróficos; além de níveis mais altos de algumas Interleucinas. O estudo demonstrou uma associação entre obesidade e indicadores de risco periodontal em adolescentes que, em longo prazo, contribuirá para uma morbidade bucal maior. Resultados semelhantes obtiveram Irigoyen-Camacho et al., em 2014, que avaliaram a associação entre indicadores de obesidade e do estado periodontal de 257 adolescentes de 15 anos na Cidade do México, verificando que o excesso de gordura corporal foi associado com sangramento à sondagem e cálculo dentário em adolescentes. Para estes autores, a relação entre o sobrepeso/obesidade e condição periodontal em adolescentes deve ser considerado em programas de prevenção de saúde bucal.

Com relação ao aspecto microbiológico da condição periodontal em adolescentes acima do peso, em 2012, Zeigler et al. testaram a hipótese de se a microbiota no biofilme bucal está relacionada com a obesidade, em 87 adolescentes obesos e eutróficos com média de idade de 14,7 anos. Os mesmos foram analisados por critérios clínicos, estimulo de saliva, e através de análise de DNA de amostras microbiológicas retiradas do sulco gengival. Os autores observaram a existência de associação entre a obesidade e a maior quantidade de células bacterianas encontradas no biofilme subgengival, indicando possível ligação da microbiota bucal e a obesidade entre os adolescentes. Entretanto estes resultados não corroboram os de Fadel et al., em 2013, que avaliaram parâmetros clínicos bucais, marcadores inflamatórios no fluido gengival e microbiota subgengival em 55 adolescentes com obesidade e eutróficos. Os resultados demonstraram que os adolescentes obesos tiveram uma taxa de secreção salivar estimulada menor, maiores concentrações de imunoglobulina A, e mais presença de gengivite; porém não apresentando diferenças nos indicadores inflamatórios e na análise microbiana subgengival.

Não há subsídios para afirmar se as alterações periodontais em adolescentes com excesso de peso são devidas às alterações sistêmicas que estão associadas com a obesidade, ou devida a possíveis hábitos de higiene bucais 
inadequados (FADEL et al., 2013). Franchini et al., em 2011, analisaram a associação entre sobrepeso/obesidade e gengivite, analisando 98 adolescentes com idades entre 10 e 17 anos. Os autores observaram que os adolescentes com sobrepeso/obesidade apresentaram uma maior presença de inflamação gengival, além de uma atitude pior para a higiene oral. Sendo assim, a gengivite observada em indivíduos jovens com sobrepeso/obesidade é provavelmente devido a uma combinação de perfis metabólicos e inflamatórios e negligência com a higiene oral. Já Cinar \& Murtomaa, em 2011, realizaram um estudo objetivando observar associações entre obesidade, saúde bucal e fatores de estilo de vida em adolescentes de 10 a 12 anos estudantes de escolas públicas e privadas em Istambul, Turquia. Analisou-se o CPOS, o CPI e fatores de estilo de vida, como frequência de escovação; sendo que os resultados demostraram que adolescentes de escolas públicas eram menos obesos e possuíam uma pior condição bucal que os de escolas privadas, sendo evidente a maior presença de cálculo dentário e pior qualidade de higienização. Para estes autores, existe uma necessidade de abordar estrategicamente a obesidade, a saúde bucal e nutrição, visando o bem-estar dos adolescentes.

A questão da higiene bucal pode inclusive ser correlacionada com problemas sistêmicos mais severos. Para Frisbee et al., em 2010, crescentes evidências epidemiológicas ligam saúde bucal, obesidade e saúde cardiovascular, acometendo também jovens. Estes autores investigaram em 128 adolescentes menores de 19 anos de idade na zona rural de West Virginia, EUA, visando determinar estas associações através de estudo das condições de higiene dentária, obesidade e análise sanguínea visando observar inflamação sistêmica. Os resultados destacam a importância do atendimento odontológico preventivo nestes adolescentes, pois houve uma relação direta entre as condições dentárias e a presença de comprometimento sistêmico. Este resultado reforça ainda mais o efeito negativo da obesidade sobre a saúde periodontal dos adolescentes, e destaca a importância de uma ação multidisciplinar entre cirurgiões-dentistas e pediatras na prevenção e tratamento da obesidade (MODÉER et al., 2011).

Com a melhora das condições bucais, particularmente relacionadas à prevalência da cárie dentária e de problemas periodontais, outros agravos à saúde bucal têm despertado maior atenção da comunidade científica (PERES \& ARMÊNIO, 2006). Segundo Freitas et al., em 2013, que utilizaram dados do SBBrasil 2003 e 
SBBrasil 2010 em seu estudo, a prevalência de fluorose tem apresentado um aumento em adolescentes, merecendo cada vez mais atenção da Saúde Pública. Em estudo sobre a associação do estado nutricional, dieta, condições de higiene e presença de fluorose, em 2010 Salcedo et al. avaliaram 51 escolares de 6 a 11 anos de idade moradores da cidade do Porto, Portugal. Os resultados demonstraram que a maioria tinha um IMC dentro da normalidade, no entanto, 35\% tinham um IMC acima do normal, o que indica risco de obesidade. $25 \%$ dos escolares apresentavam fluorose, sendo as mesmas categorizadas como "muito leves" ou "moderadas"; e o índice de fluorose comunitário foi de 0,40. Nenhuma relação significativa entre fluorose e IMC foi encontrada. Para estes autores, os resultados deste estudo indicam a necessidade de desenvolvimento de programas de promoção da saúde e aconselhamento dietético para escolares para monitorar a ingestão de flúor a partir de todas as fontes. Para isso, nutricionistas, cirurgiões-dentistas e autoridades de educação devem trabalhar em conjunto. Em estudo de Tong et al., em 2013, o objetivo foi avaliar a prevalência e associação entre erosão dentária, cárie dentária, salivação e condição nutricional, em 62 crianças e adolescentes de 7 a 15 anos de idade, habitantes da cidade de Leeds, Inglaterra. Os autores observaram que obesos eram mais propensos a ter erosão dentária do que os eutróficos, tanto em gravidade como em relação à área afetada, não havendo porém, diferenças estatisticamente significativas relacionadas à cárie dentária e a salivação.

A saliva desempenha um importante papel na prevenção das principais enfermidades bucais, como a cárie dentária, a doença periodontal e o desgaste dentário (FENOLL-PALOMARES et al., 2004), sendo portanto importante considerar a contribuição de parâmetros salivares na experiência de cárie dentária de crianças e adolescentes com excesso de peso (GUARÉ et al., 2013). Por essa razão pesquisadores objetivaram estudar a relação do fluxo salivar com o status nutricional em crianças e adolescentes. Pannunzio et al., em 2010, avaliaram se alguns parâmetros da saliva total estimulada são influenciados pelo IMC, tendo 90 crianças de 7 a 10 anos moradores da cidade de Bragança Paulista - SP como amostra. Não houve diferença no fluxo salivar entre todos os grupos, mas somente os eutróficos apresentaram valor médio considerado normal. $\mathrm{O} \mathrm{pH}$ salivar do grupo sobrepeso foi maior do que o dos eutróficos. Nos grupos sobrepeso e obeso houve decréscimo na concentração de fosfato e na atividade da peroxidase. No grupo obeso houve aumento nas concentrações de ácido siálico livre e proteína. Para os autores, 
crianças com sobrepeso e obesas apresentam alterações nas concentrações salivares de fosfato, ácido siálico livre e proteínas e na atividade da peroxidase, as quais favorecem a formação de cárie dentária. Resultados semelhantes encontraram Modéer et al., em 2010, que testaram a hipótese de se a obesidade infantil está associada a taxa de fluxo reduzido de saliva total estimulada e cárie dentária. Neste estudo foram avaliados 130 adolescentes com idade aproximada de 14 anos, que foram avaliados também em relação à cárie dentária e condição gengival. Como resultado, os indivíduos obesos apresentaram maior número de superfícies cariadas e menor taxa de fluxo de saliva total estimulada. Para os autores, isto indica que a obesidade infantil está associada a taxa de fluxo reduzido de saliva total estimulada e presença de cárie dentária, fortalecendo ainda mais efeito negativo da obesidade sobre a saúde bucal das crianças.

Com relação à associação entre más oclusões e a situação nutricional em adolescentes, Flores et al., em 2013, estudaram a prevalência de cárie, gengivite e má oclusão em 402 escolares de 7 a 12 anos em Ciudad Victoria, México, correlacionando com o estado nutricional. Os autores observaram que 36,2\% estavam com sobrepeso/obesidade, 87,0\% apresentavam cárie dentária, 63,0\% gengivite, e 33,0\% algum tipo de má oclusão.

\subsection{QUALIDADE DE VIDA E SAÚDE BUCAL EM ADOLESCENTES COM SOBREPESO/OBESIDADE}

Para a Organização Mundial de Saúde, a qualidade de vida pode ser definida como "a percepção do individuo de sua posição na vida, no contexto da cultura e do sistema de valores nos quais ele vive, e em relação aos seus objetivos, expectativas, padrões e preocupações" (WHO, 1997).

Observa-se que a qualidade de vida dos indivíduos pode receber influências significativas de alguns problemas bucais, como dor, desconforto, limitações e outras condições decorrentes de fatores estéticos que afetam a vida social, a alimentação, o exercício de atividades diárias e o bem-estar do indivíduo (LEÃO et al., 1998).

A promoção da saúde entre os adolescentes é de extrema importância visando a melhora da qualidade de vida (FREITAS et al., 2014). Pode significar o quanto seus desejos e esperanças se aproximam do que realmente acontece em 
suas vidas (BARBOSA et al., 2010). Adultos, crianças e adolescentes possuem diferentes percepções sobre o impacto da saúde bucal na qualidade de vida, pois as mesmas têm uma visão peculiar de si mesmos e do mundo a despeito da fase de desenvolvimento físico e psicológico em que se encontram (PIOVESAN et al., 2009).

As informações a respeito da qualidade de vida relacionada à saúde bucal são mensuradas frequentemente através de questionários autoaplicáveis denominados indicadores sociodentais ou sócio-odontológicos (SLADE, 1998), sendo que estes questionários têm se tornado cada vez mais usuais em pesquisas científicas, avaliações clínicas e na avaliação de ações de políticas públicas (BARBOSA et al., 2010). Esse indicadores têm sido desenvolvidos e testados epidemiologicamente em diferentes populações a fim de se estruturar, de maneira mais concreta, as relações entre medidas subjetivas e objetivas de saúde bucal, contribuindo para uma estimativa mais clara das necessidades de uma determinada população (LEÃO \& LOCKER, 2006).

Um dos questionários mais utilizados em adolescentes é o CHILD-OIDP, adaptação do questionário indicado para adultos OIDP (Oral Impacts on Daily Performances) (ADULYANON et al., 1996). Na versão brasileira do mesmo, avaliase o impacto das condições de saúde bucal nas atividades diárias dos adolescentes entre 11 à 14 anos, sendo que na primeira parte do questionário o adolescente é solicitado a recordar todos os problemas relacionados à saúde bucal que ele teve experiência nos últimos 3 meses, e a segunda parte consiste de uma entrevista para verificar a presença de impactos relacionados aos problemas bucais nas atividades de comer, falar, higienização bucal, dormir, estado emocional, sorrir, estudar e contato social (CASTRO et al., 2008). Chakravathy et al., em 2013, avaliaram a relação do índice de massa corporal (IMC) e a cárie dentária com a qualidade de vida relacionada à saúde bucal utilizando o CHILD-OIPD. Foram avaliados 456 adolescentes entre 13 e 15 anos, moradores de Udupi, Índia. Observou-se que a prevalência dos impactos variaram 7,4-32,8\% para adolescentes baixopeso/eutróficos, e 12,9-49,7\% em adolescentes com sobrepeso/obesidade. Houve uma média significativamente mais elevada para adolescentes com sobrepeso/obesidade do que para baixopeso/eutróficos para as atividades relacionados a "comer", "falar", "dormir", "sorridente" e "estado emocional", e na pontuação total do CHILD-OIDP e prevalência da cárie dentária. O IMC e dentes 
cariados apresentaram associação significativa com a pontuação CHILD-OIDP. Para os autores, os adolescentes com cárie dentária e aumento de IMC tiveram baixa qualidade de vida relacionada à saúde bucal. Em um estudo sobre a associação entre obesidade infantil e o impacto bucal na qualidade de vida, os autores observaram a influência de aspectos psicológicos (sorrir e estado emocional) na qualidade de vida dos adolescentes portadores de sobrepeso/obesidade. No mesmo estudo foi possível correlacionar os valores do índice CPOD com o estado emocional e a atividade de cárie dentária com o desempenho escolar nesses adolescentes, ainda que os indivíduos com peso adequado tivessem apresentado maior percepção de impacto das condições bucais na qualidade de vida (FREITAS et al., 2014). 


\section{Proposicano}



3 PROPOSIÇÃO

\subsection{OBJETIVO GERAL}

O presente estudo teve por objetivo analisar a relação entre as condições de saúde bucal e a qualidade de vida de adolescentes com sobrepeso/obesidade e eutróficos aos 12 anos, estudantes da rede pública, no município de Bauru, Estado de São Paulo.

\subsection{OBJETIVOS ESPECÍFICOS}

$\checkmark$ Avaliar o estado nutricional dos adolescentes por meio do Índice de Massa Corpórea (IMC);

$\checkmark$ Avaliar as condições de saúde bucal quanto à cárie dentária, fluorose dentária, condições periodontais, desgaste dentário, má oclusão e fluxo salivar em adolescentes com sobrepeso/obesidade e eutróficos;

$\checkmark$ Avaliar os impactos odontológicos no desempenho das atividades diárias dos adolescentes, por meio do questionário CHILD-OIDP em adolescentes com sobrepeso/obesidade e eutróficos;

$\checkmark$ Analisar a relação entre as condições bucais e a qualidade de vida em adolescentes com sobrepeso/obesidade e eutróficos. 



\section{Material e Métodos}



4 MATERIAL E MÉTODOS

\subsection{ASPECTOS ÉTICOS}

O presente projeto foi encaminhado para apreciação do Comitê de Ética em Pesquisa da Faculdade de Odontologia de Bauru (CEP FOB-USP), sendo aprovado pelo parecer CAAE: 06395012.8.0000.5417 (Anexo A). Foram enviados termos de consentimento livre e esclarecido (TCLE) aos pais ou responsáveis pelos adolescentes, visando autorização para participação dos mesmos na pesquisa. No TCLE foram descritos os objetivos da pesquisa assim como os possíveis riscos e benefícios e a forma de realização dos exames, garantindo o sigilo das informações e a participação voluntária no estudo.

\subsection{OPÇÃO METODOLÓGICA}

Foi realizado um estudo observacional e de investigação transversal, objetivando avaliar o estado nutricional, as condições bucais e os impactos odontológicos no desempenho das atividades diárias, de escolares aos 12 anos residentes no município de Bauru, Estado de São Paulo.

\subsection{CRITÉRIOS DE INCLUSÃO E EXCLUSÃO}

Os critérios de inclusão adotados neste estudo foram: a autorização dos pais para a participação de seus filhos por meio do termo de consentimento livre e esclarecido devidamente assinado, os adolescentes possuírem no dia dos exames 12 anos, a presença do adolescente no dia do exame e a ausência de aparelho ortodôntico fixo. Foram excluídos da amostra, os indivíduos que não quiseram ou desistiram de participar desta pesquisa por qualquer razão.

\subsection{CÁLCULO DA AMOSTRA}

O cálculo amostral foi realizado utilizando-se dados fornecidos pela Secretaria Municipal de Educação do Bauru - SP, relativos ao número de adolescentes com 12 anos regularmente matriculados na rede pública municipal de 
ensino fundamental. O coeficiente de correlação utilizado foi 0,20, adotando-se nível de erro alfa de $5 \%$ e nível de erro beta de $20 \%$. O valor mínimo para o efeito de desenho foi de 140 adolescentes e o valor máximo de 196, estimando as perdas.

\subsection{COMPOSIÇÃO DA AMOSTRA}

O presente estudo foi realizado no município de Bauru - SP, que está localizado na região centro-oeste do estado de São Paulo, em uma área territorial de $667.681 \mathrm{~km}^{2}$, e de acordo com o Censo do Instituto Brasileiro de Geografia e Estatística (IBGE) em 2010, contava com 343.937 habitantes (BRASIL, 2014).

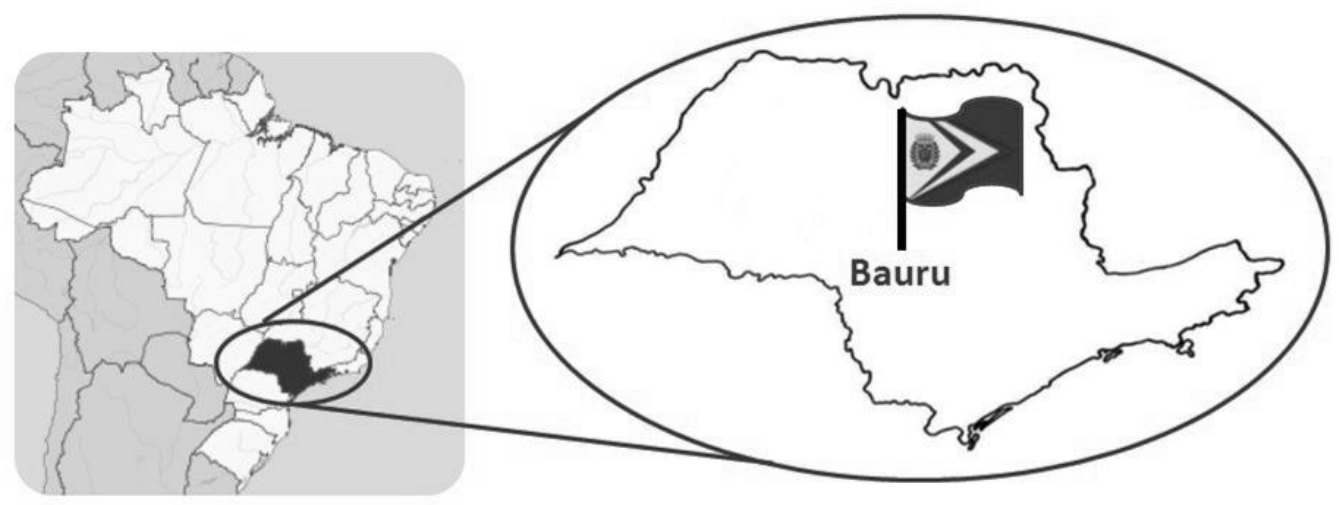

Figura 1 - Localização do Município de Bauru - Estado de São Paulo

A Secretaria Municipal de Educação de Bauru - SP foi contatada para a apresentação do projeto de pesquisa e obtenção da autorização para a realização deste estudo (Anexo B). Posteriormente as escolas integrantes da rede municipal de ensino foram contatadas com a mesma finalidade. As mesmas foram informadas sobre este estudo por meio de uma carta de informação (Anexo C), entregue aos diretores das instituições. Os pais ou responsáveis dos adolescentes que frequentam as escolas foram informados sobre a pesquisa por meio do consentimento pós-informado. Só participaram da pesquisa aqueles adolescentes cujos pais ou responsáveis autorizaram que os mesmos fizessem parte da casuística.

A amostra foi constituída por adolescentes estudantes da rede pública municipal de ensino, residentes no Município de Bauru - SP, utilizando-se a faixa etária de 12 anos, como preconizado pela OMS. Para a realização da pesquisa, todas as escolas da rede pública municipal foram pré-selecionadas, sendo ao final 
escolhidas as cinco escolas de ensino fundamental que possuíam alunos na faixa etária de 12 anos. A lista contendo os nomes das escolas e as regiões do município contempladas, é apresentada na Tabela 1; sendo que a região leste do município não pode ser contemplada, pois não havia escola da rede municipal de ensino disponível com alunos na faixa etária de estudo.

Os exames foram realizados no período de 05 a 09 de Novembro de 2012, nas escolas apresentadas, onde se encontravam os escolares convidados a participar do estudo.

Tabela 1 - Frequência absoluta dos TCLEs distribuídos, e frequência absoluta e relativa de adolescentes examinados nas escolas municipais, Bauru - SP, 2011

\begin{tabular}{ccc}
\hline Escola & \multicolumn{2}{c}{ Alunos examinados } \\
\hline & $\mathrm{N}$ & $\%$ \\
\hline EMEF Ivan Engler de Almeida (Região Oeste) & 27 & $17,6 \%$ \\
EMEF Cônego Aníbal Difrância (Região Norte) & 37 & $24,2 \%$ \\
EMEF Santa Maria (Centro) & 35 & $22,9 \%$ \\
EMEF Nacilda de Campos (Região Norte) & 43 & $28,1 \%$ \\
NER Lydya Alexandrina Nava Cury (Região Sul) & 11 & $7,2 \%$ \\
\hline Total & 153 & $100 \%$ \\
\hline
\end{tabular}

\subsection{ETAPAS DO ESTUDO}

O presente estudo foi composto pelas seguintes etapas:

$\checkmark$ Calibração dos examinadores;

$\checkmark$ Apresentação do projeto e distribuição TCLEs;

$\checkmark$ Avaliação epidemiológica;

$\checkmark$ Análise estatística.

\subsubsection{CALIBRAÇÃO DOS EXAMINADORES}

A Organização Mundial de Saúde (WHO, 1997) preconiza a padronização e calibração dos examinadores a qual tem por objetivo assegurar a interpretação, o entendimento e aplicação uniformes dos critérios para as doenças e condições a 
serem observadas e registradas a fim de assegurar que cada profissional possa examinar dentro de um padrão consistente assim como minimizar variações entre diferentes examinadores.

O processo de calibração dos examinadores foi conduzido por um examinador padrão, experiente em levantamentos epidemiológicos, sendo a primeira etapa deste processo constituída por aula teórica, a fim de se buscar a padronização inicial quanto aos códigos, critérios e condutas adotadas para o estudo. Na segunda etapa foi realizada uma demonstração clínica, pelo examinador padrão, quanto ao posicionamento dos examinadores e anotadores, organização do material de trabalho, fichas clínicas e ergonomia em relação ao atendimento, seguidos de exames de treinamento e discussão clínica para familiarização dos procedimentos.

Foi calculado o coeficiente kappa para mensurar a concordância, intra e inter-examinadores, sendo realizado o re-teste em $10 \%$ de amostra (LANDIS \& $\mathrm{KOCH}, 1977)$. Os coeficientes kappa obtidos foram 0,88 para cárie dentária, 0,79 para condição periodontal, 0,76 para índice de fluorose e 0,87 para o índice de desgaste dentário.

\subsubsection{APRESENTAÇÃO DO PROJETO E DISTRIBUIÇÃO DOS TERMOS DE CONSENTIMENTO LIVRE E ESCLARECIDO (TCLE)}

Foram realizadas visitas às escolas previamente à realização dos exames, a fim de se apresentar a diretores, professores e responsáveis as proposições do estudo e esclarecer quanto à participação dos escolares através da distribuição do TCLE, assim como solicitar autorização dos mesmos para a condução da pesquisa (Anexo D).

Foi realizada uma explanação em cada sala de aula sobre a proposição da pesquisa aos adolescentes e foram entregues os TCLEs com a finalidade de obter autorização dos pais ou responsáveis dos alunos para sua participação no estudo, visto que os mesmos apresentavam idade inferior à 18 anos. Posteriormente os termos foram recolhidos nas salas de aula para proceder a realização dos exames clínicos.

\subsubsection{AVALIAÇÃO EPIDEMIOLÓGICA}


A etapa de avaliação epidemiológica do presente estudo foi composta pelas seguintes fases:

$\checkmark$ Análise antropométrica

$\checkmark$ Aplicação de questionário

$\checkmark$ Exames clínicos

Para a realização da avaliação epidemiológica, os adolescentes foram chamados em grupos de 3 indivíduos, e enquanto o primeiro tinha sua antropometria aferida, os demais preenchiam os questionários, alternando na sequência. Posteriormente os mesmos eram encaminhados para os exames clínicos. Esta sequência de procedimentos foi adotada para evitar falhas no preenchimento dos questionários, assim como evitar perdas decorrentes de falta de entrega dos mesmos.

\subsubsection{ANÁLISE ANTROPOMÉTRICA}

A avaliação antropométrica foi realizada por meio do Índice de Massa Corpórea (IMC) e analisada posteriormente de acordo com os pontos de corte e percentis, para faixa etária e gênero dos indivíduos avaliados (WHO, 2007). Foi utilizada fita métrica e uma balança, devidamente calibrada, e os escolares foram solicitados a retirar os sapatos para a aferição das medidas de peso $(\mathrm{kg})$ e altura $(\mathrm{m})$ (Figura 2). Estas medidas foram registradas para o posterior cálculo do IMC, de acordo com a equação abaixo:

$$
I M C=\frac{\text { peso }(\mathrm{kg})}{\operatorname{altura}^{2}(\mathrm{~m})^{2}}
$$

A avaliação antropométrica foi realizada empregando-se o Índice de Massa Corporal (IMC) por idade $\left(\mathrm{kg} / \mathrm{m}^{2}\right)$, utilizado pela Organização Mundial de Saúde como instrumento de medida de crescimento e nutrição (WHO, 2007). O IMC por idade depende do sexo e da relação peso/altura, sendo variável para as idades entre 5 a 19 anos. Esta avaliação foi usada para distribuir os adolescentes em dois grupos: Sobrepeso/obesidade (SPO), com percentil de IMC $\geq 85$, e Eutróficos (EUT) com IMC $\geq 3 \leq$ percentil 85 . 


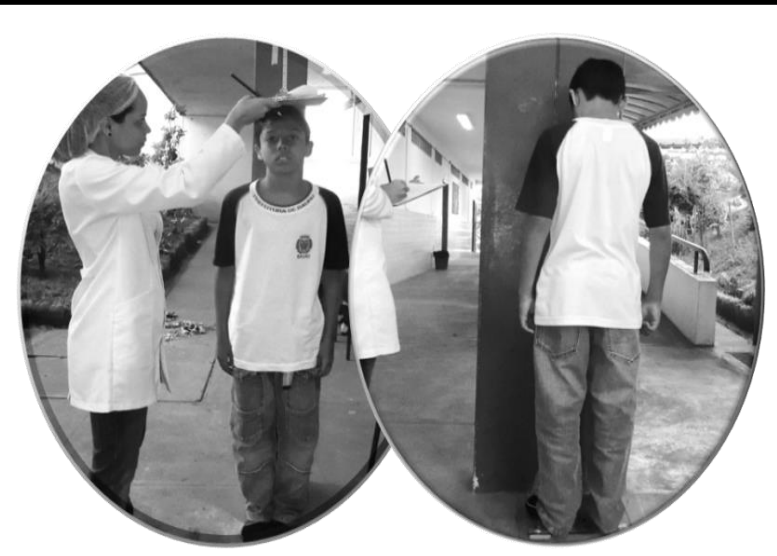

Figura 2 - Aferição da altura e do peso dos adolescente para a antropometria.

\subsubsection{EXAMES CLÍNICOS}

Os exames clínicos foram realizados por examinadores e anotadores devidamente calibrados, sendo conduzidos no pátio das escolas, sob iluminação natural, com o examinador e o adolescente sentados um de frente ao outro, de acordo com as normas preconizadas pela Organização Mundial de Saúde (WHO, 1997). Utilizou-se gaze para limpeza e secagem das superfícies dentárias, espelhos bucais planos $n^{\circ} 5$ e sondas periodontais OMS (WHO,1997) (Figura 3), a fim de se confirmar evidências visuais de cárie dentária e realização de exames das condições periodontais, bem como presença de fluorose dentária, desgaste dentário e máoclusão. O número de instrumentos já previamente esterilizados utilizados para os exames, eram em número suficiente visando preencher os critérios de biossegurança necessários para a realização deste estudo.

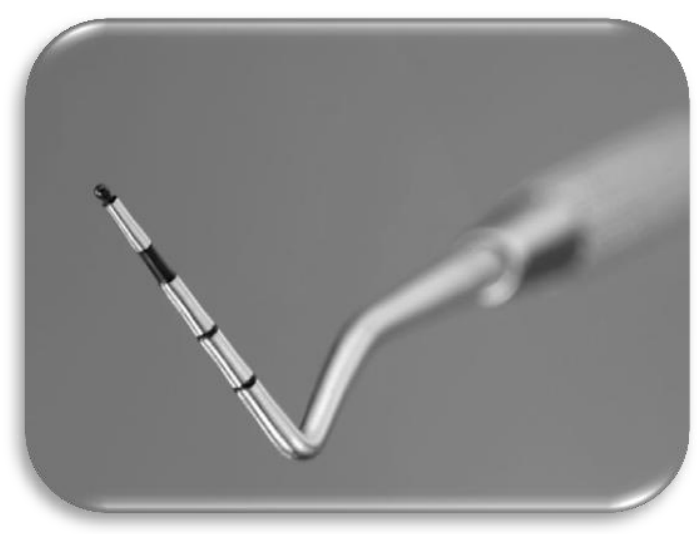

Figura 3 - Sonda periodontal preconizada pela OMS (WHO, 1997) 
Para a avaliação das condições de saúde bucal dos escolares foram utilizados os índices ceod e CPOD para cárie dentária (WHO, 1997), índice de Dean para fluorose dentária (DEAN, 1934), índice IPC para doença periodontal (WHO, 1997), índice IDD para desgaste dentário (SALES-PERES, 2008), índice DAI para má oclusão (WHO, 1997), e análise do fluxo salivar. Os dados obtidos foram anotados em ficha própria (Anexo E), para facilitar a tabulação dos dados.

Cárie Dentária

$\mathrm{Na}$ avaliação das condições bucais para cárie dentária utilizou-se os índices ceod e CPOD (WHO, 1997); sendo que para realizar o cálculo dos dois índices e de seus componentes, todos os dentes examinados receberam um código baseado na sua condição clínica conforme o apresentado no Quadro 1. Quando da necessidade de tratamento, os códigos e condições empregados como critério estão descritos no Quadro 2.

Quadro 1 - Códigos e condições empregados nos índices ceod e CPOD

\begin{tabular}{|c|c|c|c|}
\hline \multicolumn{3}{|c|}{ Código } & \multirow[t]{2}{*}{ Condição } \\
\hline Coroa & Coroa & Raiz & \\
\hline A & 0 & 0 & Hígido \\
\hline B & 1 & 1 & Cariado \\
\hline C & 2 & 2 & Restaurado e com cárie \\
\hline D & 3 & 3 & Restaurado e sem cárie \\
\hline $\mathbf{E}$ & 4 & - & Dente perdido devido à cárie \\
\hline- & 5 & - & Dente perdido por outras razões \\
\hline $\mathbf{F}$ & 6 & - & Selante de fissura \\
\hline G & 7 & 7 & Apoio de ponte, coroa ou Venner \\
\hline- & 8 & 8 & Coroa não erupcionada \\
\hline $\mathbf{T}$ & $\mathbf{T}$ & - & Traumatismo \\
\hline- & 9 & 9 & Não informado \\
\hline
\end{tabular}


Quadro 2 - Códigos e condições empregados para necessidade de tratamento

\begin{tabular}{|cc|}
\hline Código & Condição \\
\hline $\mathbf{0}$ & Nenhum tratamento \\
$\mathbf{P}$ & Prevenção / medidas para a inativação de cárie \\
$\mathbf{F}$ & Selante de fissura \\
$\mathbf{1}$ & Restauração de 1 superfície \\
$\mathbf{2}$ & Restauração de 2 ou mais superfícies \\
$\mathbf{3}$ & Coroa por qualquer razão \\
$\mathbf{4}$ & Veneer ou coroa laminada \\
$\mathbf{5}$ & Cuidado pulpar e restauração \\
$\mathbf{6}$ & Extração indicada \\
7 ou 8 & Necessidades de outros cuidados \\
$\mathbf{9}$ & Não Informado \\
\hline
\end{tabular}

Também utilizou-se para a análise dos resultados em relação a cárie dentária o Índice significativo de cárie (SIC Index), proposto para avaliar a desigualdade de cárie dentária na população em estudo. É representado pelo valor médio do CPOD calculado para um terço do grupo examinado que apresentou os valores mais elevados de cárie dentária (ANTUNES et al., 2006).

\section{Fluorose Dentária}

Para a avaliação da presença de fluorose dentária foi empregado o Índice de Dean (DEAN, 1934), que inclui seis categorias (normal, questionável, muito leve, leve, moderada e severa), de acordo com as alterações estéticas e estruturais provocadas pelo consumo excessivo de flúor nos dois dentes mais acometidos. Em caso de dúvidas sobre a presença ou não de fluorose, deve-se considerar o dente como normal (Quadro 3).

Utilizou-se também o índice de fluorose da comunidade (DEAN, 1934), que objetiva facilitar a interpretação da fluorose no âmbito da saúde pública. Este índice é calculado a partir da média aritmética dos graus atribuídos a cada indivíduo (Quadro 4) de acordo com a seguinte fórmula: 


\section{$\sum$ (Frequência $X$ grau) $/ n$ \\ $n=$ número de sujeitos da amostra.}

Quadro 3 - Códigos, classificação e critérios do Índice de Dean (DEAN, 1934)

\section{Código Classificação Características clínicas}

0

O esmalte apresenta-se translúcido, de estrutura

Normal vitriforme, superfície lisa, lustrosa, usualmente de cor

branco-creme pálido

O esmalte mostra discretas aberrações na translucidez

1 Questionável que podem ir desde pequenos traços esbranquiçados até manchas ocasionais

Pequenas e opacas áreas brancas espalhadas pelo dente

2 Muito leve não envolvendo mais que $25 \%$ da superfície (1 a $2 \mathrm{~mm}$ a partir do topo da cúspide)

Áreas brancas não envolvendo mais que 50\% da superfície

Toda a superfície está afetada; as superfícies estão sujeitas ao desgaste; manchas marrons frequentes Toda a superfície está afetada, e há hipoplasia com

$5 \quad$ Severa mudança da anatomia dentária; manchas marrons, erosões e aparência de corrosão

Quadro 4 - Índices, classificação e interpretação do índice de fluorose dentária da comunidade (DEAN, 1934)

\begin{tabular}{|c|c|c|}
\hline Índice & Classificação & Interpretação \\
\hline $\begin{array}{l}0,0 \text { a } 0,4 \\
0,4 \text { a } 0,6\end{array}$ & $\begin{array}{l}\text { Negativo } \\
\text { Zona Limítrofe }\end{array}$ & $\begin{array}{c}\text { Índice sem importância para a saúde pública sob o } \\
\text { ponto de vista da fluorose, porém de alto valor sob o } \\
\text { ponto de vista de prevenção de cárie }\end{array}$ \\
\hline 0,6 a 1,0 & Leve & \\
\hline 1,0 a 2,0 & Médio & Recomendada a remoção de excesso \\
\hline 2,0 a 3,0 & Grave & de flúor na água \\
\hline 3,0 a 4,0 & Muito Grave & \\
\hline
\end{tabular}


Condição Periodontal

A condição de saúde periodontal foi avaliada pelo Índice Periodontal Comunitário (IPC) (WHO, 1997), de acordo com os códigos e critérios utilizados no Projeto SB Brasil 2010 (BRASIL, 2011). Este índice permite avaliar a condição periodontal quanto à higidez, presença de sangramento e de cálculo.

Neste exame, a boca foi dividida em sextantes definidos pelos dentes 17 e 16, 11, 26 e 27, 46 e 47, 31, 36 e 37. A presença de dois ou mais dentes sem indicação de exodontia, foi pré-requisito ao exame do sextante. O sextante foi anotado com um " $X$ " quando inexistiam dentes para o exame ou quando só um elemento dentário estava presente ou ainda na presença de qualquer número de dentes indicados para extração. As condições aferidas foram registradas, para cada possível desfecho (Quadro 5).

No exame, pelo menos 6 pontos foram examinados em cada um dos dentes-índices, nas superfícies vestibular e lingual, abrangendo as regiões mesial, média e distal. Os procedimentos de exame foram iniciados pela área distovestibular, passando-se para a área média e, na sequência, para área mésiovestibular. Posteriormente, inspecionaram-se as áreas linguais, de distal para mesial.

Quadro 5 - Códigos, condições e critérios do IPC (BRASIL, 2011; WHO,1997)

\begin{tabular}{|c|c|c|}
\hline Código & Condição & Critérios \\
\hline 0 & Hígido & Sem problemas periodontais \\
\hline 1 & Sangramento & $\begin{array}{l}\text { Observado visualmente ou pelo espelho, após } \\
\text { sondagem }\end{array}$ \\
\hline 2 & Cálculo & $\begin{array}{l}\text { Qualquer quantidade existente, mantendo-se toda a } \\
\text { banda colorida da sonda visível }\end{array}$ \\
\hline $\mathrm{x}$ & Nulo & $\begin{array}{l}\text { Sextante excluído por ter menos de dois dentes } \\
\text { presentes }\end{array}$ \\
\hline 9 & Não informado & \\
\hline
\end{tabular}

Para a realização deste exame, empregou-se a sonda OMS já descrita anteriormente. A mesma foi introduzida levemente no sulco gengival, ligeiramente 
inclinada em relação ao longo eixo do dente, seguindo a configuração anatômica da superfície radicular. Movimentos de vai-e-vem vertical, de pequena amplitude, foram realizados.

\section{Desgaste Dentário}

Para a avaliação do desgaste dentário foi adotado o Índice de Desgaste Dentário (IDD) que permite avaliar a prevalência e a severidade do desgaste (SalesPeres et al., 2008) (Quadro 6). A realização deste exame foi precedida por secagem das superfícies dentárias com gaze, facilitando o diagnóstico visual.

O valor foi obtido pela razão entre número de faces com desgaste e o número total de faces avaliadas, sendo multiplicado por 100. Dessa forma, obtevese uma porcentagem de faces com desgaste, podendo ser calculado de acordo com o substrato envolvido, esmalte ou dentina.

Quadro 6 - Códigos, condições e critérios do IDD (Sales-Peres et al., 2008)

\begin{tabular}{|c|c|c|c|}
\hline Decíduos & $\begin{array}{l}\text { score } \\
\text { Permanentes }\end{array}$ & Condição & Critério \\
\hline A & 0 & Normal & $\begin{array}{l}\text { Sem evidência de desgaste - nenhuma } \\
\text { perda nas características do esmalte }\end{array}$ \\
\hline B & 1 & Incipiente & $\begin{array}{c}\text { Desgaste em esmalte - perda nas } \\
\text { características da superfície do esmalte, } \\
\text { sem envolvimento da dentina }\end{array}$ \\
\hline C & 2 & Moderado & $\begin{array}{c}\text { Desgaste envolvendo dentina - perda de } \\
\text { esmalte com exposição da dentina }\end{array}$ \\
\hline D & 3 & Severo & $\begin{array}{l}\text { Desgaste se estendendo até a polpa - } \\
\text { extensa perda de esmalte e dentina com } \\
\text { exposição de dentina } 2^{\text {aria }} \text { ou da polpa }\end{array}$ \\
\hline$E$ & 4 & Restaurado & $\begin{array}{c}\text { Restaurado por causa de desgaste - o } \\
\text { dente recebeu tratamento restaurador } \\
\text { devido ao desgaste }\end{array}$ \\
\hline 9 & 9 & Sem registro & $\begin{array}{l}\text { Cáries extensas, restauração grande, } \\
\text { dente com fratura ou dente ausente }\end{array}$ \\
\hline
\end{tabular}


Má Oclusão Dentária

O índice DAI (Dental Aesthetic Index), é utilizado para avaliação de oclusopatias (WHO, 1997). O seu princípio básico é uma combinação de medidas (não somente de problemas oclusais) as quais, em seu conjunto, expressam o estado oclusal do indivíduo e, consequentemente, sua necessidade de tratamento, devido à composição do índice que considera comprometimento estético além da oclusão. Nesse estudo foi utilizado o índice DAl adaptado (Quadro 7).

Quadro 7 - Dimensões, situação e código/critério do DAI (WHO,1997) adaptado

\begin{tabular}{|c|c|c|}
\hline Dimensão & Situação & Código-critério \\
\hline Dentição & Condição da dentição & $\begin{array}{c}\text { Número de incisivos molares e } \\
\text { pré-molares que causam } \\
\text { problemas estéticos }\end{array}$ \\
\hline Espaço & $\begin{array}{l}\text { Apinhamento no segmento } \\
\text { incisal } \\
\text { Espaçamento no segmento } \\
\text { incisal }\end{array}$ & $\begin{array}{l}0 \text { - Sem apinhamento } \\
\text { 1- Apinhamento em } 1 \text { segmento } \\
\text { 2- Apinhamento em } 2 \text { segmentos } \\
0 \text { - Sem espaçamento } \\
\text { 1- Espaçamento em } 1 \text { segmento } \\
\text { 2- Espaçamento em } 2 \text { segmentos }\end{array}$ \\
\hline Oclusão & $\begin{array}{l}\text { Overjet maxilo-mandibular } \\
\text { Mordida aberta anterior }\end{array}$ & $\begin{array}{c}\text { Medida da sobressaliência anterior } \\
\text { em milímetros } \\
\text { Medida em milímetros } \\
0 \text { - normal } \\
1 \text { - relação de } 1 / 2 \text { classe II } \\
2 \text { - relação de classe II total } \\
3 \text { - relação de } 1 / 2 \text { classe III } \\
4 \text { - relação de classe III total }\end{array}$ \\
\hline
\end{tabular}

Após a soma dos escores obtidos no DAl, os indivíduos foram classificados de acordo com a severidade apresentada (Quadro 8) (WHO, 1997). 
Quadro 8 - Classificação da má oclusão com relação à severidade

\begin{tabular}{|ccc|}
\hline Severidade da má oclusão & Indicação de tratamento & DAl \\
\hline Sem anormalidades ou oclusopatia leve & Sem necessidade ou & $\leq 25$ \\
Má oclusão definida & necessidade leve & \\
Má oclusão severa & Eletivo & $26-30$ \\
Má oclusão muito severa & Altamente desejável & $31-35$ \\
& Fundamental & $\geq 36$ \\
\hline
\end{tabular}

Fluxo Salivar

A avaliação do fluxo salivar dos adolescentes foi realizada após a coleta da saliva obtida por meio de estimulação mecânica. Para a realização desta coleta foi utilizado um fragmento de tubo de látex de $0,5 \mathrm{~cm}$ preso a um cordão de $30 \mathrm{~cm}$ de fio dental, a fim de se evitar a deglutição do dispositivo, que foram esterilizados previamente ao uso. Foi solicitado ao adolescente que introduza a borracha na boca e inicie a mastigação, descartando-se a primeira saliva. Após um minuto do início do estímulo foi oferecido ao adolescente um copo plástico descartável de $50 \mathrm{ml}$, onde foi depositada toda a saliva produzida, durante um período de cinco minutos. Ao final da coleta o volume de saliva obtido foi aferido por meio de uma seringa plástica milimetrada descartável (Figura 4).

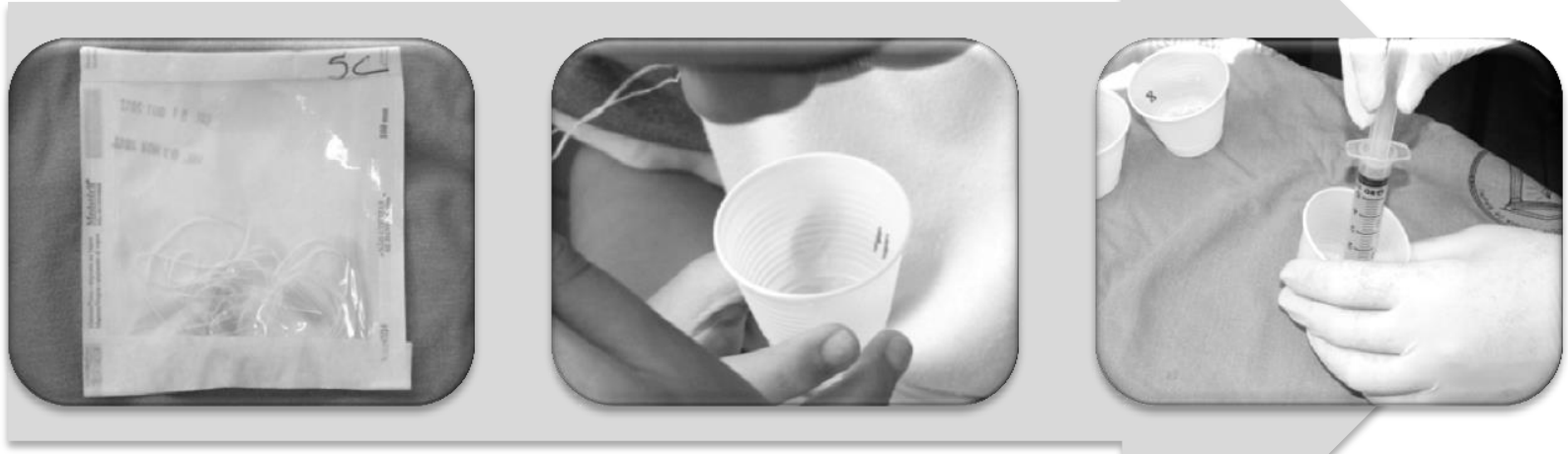

Figura 4 - Sequência realizada para aferição do volume da saliva (ml/min) 
O volume obtido foi dividido por cinco (cinco minutos de coleta), para a obtenção do fluxo salivar em $\mathrm{ml} / \mathrm{min}$, considerando-se normais os valores entre um e três $\mathrm{ml} / \mathrm{min}$ (NAVARRO \& CORTES, 1995; GREENWAY \& GREENWAY, 2000) (Quadro 9).

Quadro 9 - Parâmetros para a avaliação do fluxo salivar

\begin{tabular}{|cc|}
\hline Fluxo Salivar & Volume $/$ minuto \\
\hline Normal & 1,0 a $3,0 \mathrm{ml}$ \\
Hipossalivação & Abaixo de $1,0 \mathrm{ml}$ \\
\hline
\end{tabular}

\subsubsection{APLICAÇÃO DE QUESTIONÁRIO}

Para a avaliação dos impactos odontológicos no desempenho das atividades diárias dos adolescentes foi utilizado o questionário adaptado e validado por Castro et al. (2008), o Índice de Impactos Odontológicos no Desempenho das Atividades Diárias da Criança (CHILD-OIDP). A aplicação deste questionário (Anexo F) consiste em uma entrevista que foi realizada logo após os exames antropométricos e clínicos dos adolescentes. A mesma foi realizada em duas etapas, sendo que a primeira etapa visou identificar os problemas bucais percebidos pelos escolares; e a segunda etapa avaliar os impactos bucais na qualidade de vida dos escolares.

Os questionários empregados objetivavam avaliar o impacto das condições bucais nas atividades de comer, falar, higienização bucal, dormir, estado emocional, sorrir, estudar e contato social. Quando os adolescentes relataram um impacto no desempenho dessas atividades diárias, eles responderam perguntas sobre a gravidade e a frequência desse impacto específico (escore 0-3); sendo o cálculo geral do índice feito pela multiplicação da gravidade e frequência em cada atividade. A soma dos oito valores das atividades obtidas, que resultou em um número $0-72$, foi dividido por 72 e depois multiplicado por 100. Portanto, a pontuação CHILD-OIDP varia de 0-100, aonde quanto maior este valor, maior o impacto da condição bucal nas atividades diárias avaliadas dos adolescentes. 


\subsubsection{ANALISE ESTATÍSTICA}

Os dados coletados foram tabulados e organizados com dupla entrada, em arquivos do programa Excel 2010 (Microsoft Office, 2010). A apresentação foi constituída de uma parte descritiva, médias e desvios-padrão, por meio de tabelas e gráficos.

Em relação à análise estatística, inicialmente foi aplicado o teste de normalidade e homogeneidade dos dados, sendo então empregado o teste estatístico apropriado. Havendo distribuição normal e homogeneidade dos desviospadrão, foi empregado o teste t-Student, para avaliar as diferenças entre os grupos. Caso contrário, empregou-se um teste não paramétrico (Mann-Whitney). Com o intuito de verificar a relação entre as variáveis foram aplicados teste Qui-Quadrado, Odds Ratio (dados não paramétricos) e o Coeficiente Linear de Correlação de Pearson (dados paramétricos).

O programa estatístico STATISTICA 7 (Stat Soft Inc., USA) foi utilizado para a análise dos dados, adotando-se nível de significância de 5\% ( $p<0,050$ ). 

5 Resultados 



\section{RESULTADOS}

\subsection{CARACTERIZAÇÃO DA AMOSTRA}

A amostra foi composta por adolescentes aos 12 anos de idade, regularmente matriculados na rede pública municipal de ensino de Bauru - SP. Participaram da pesquisa 153 adolescentes, que foram subdivididos em dois grupos (G1 e G2), conforme o IMC. Em G1 foram alocados os adolescentes que apresentaram Sobrepeso/Obesidade (SPO) - 40,52\%, e em G2 os adolescentes Eutróficos (EUT) - 59,48\% (Gráfico 1).

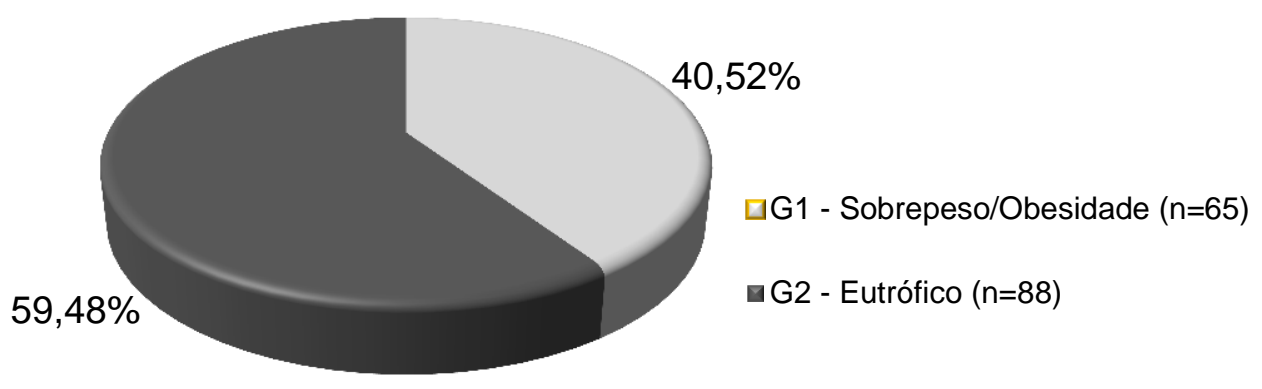

Gráfico 1 - Porcentagem da amostra com SPO e EUT

No G1, a média do IMC encontrado foi 22,98 $\pm 3,39$ (masculino) e $23,78 \pm 3,23$ (feminino); enquanto que no $G 2$ observou-se 16,95 $\pm 1,40$ (masculino) e 17,41 $\pm 1,46$ (feminino). Proporcionalmente, o gênero feminino esteve mais presente em G1, enquanto masculino em G2 (Gráfico 2).

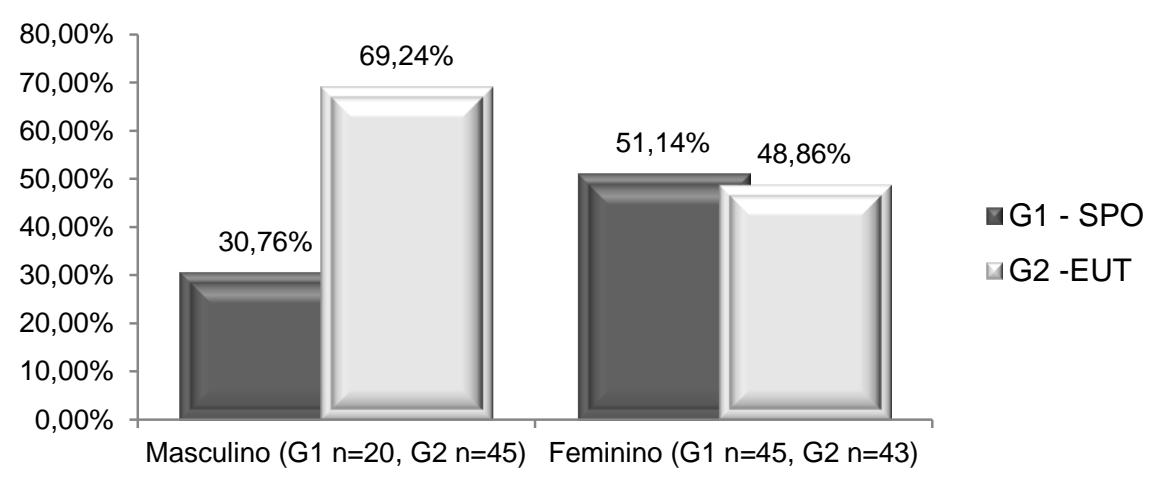

Gráfico 2 - Concentração por gênero nos grupos SPO e EUT 
5.2 CONDIÇÕES DE SAÚDE BUCAL

Para a realização da presente pesquisa, foram avaliadas as seguintes condições de saúde bucal dos adolescentes: Cárie dentária, fluorose dentária, condição periodontal, desgaste dentário, má oclusão dentária e fluxo salivar.

\subsubsection{Cárie dentária}

O G1 apresentou uma maior percentagem de adolescentes livres de cárie, ou seja, com CPOD igual a 0 (Gráfico 3).

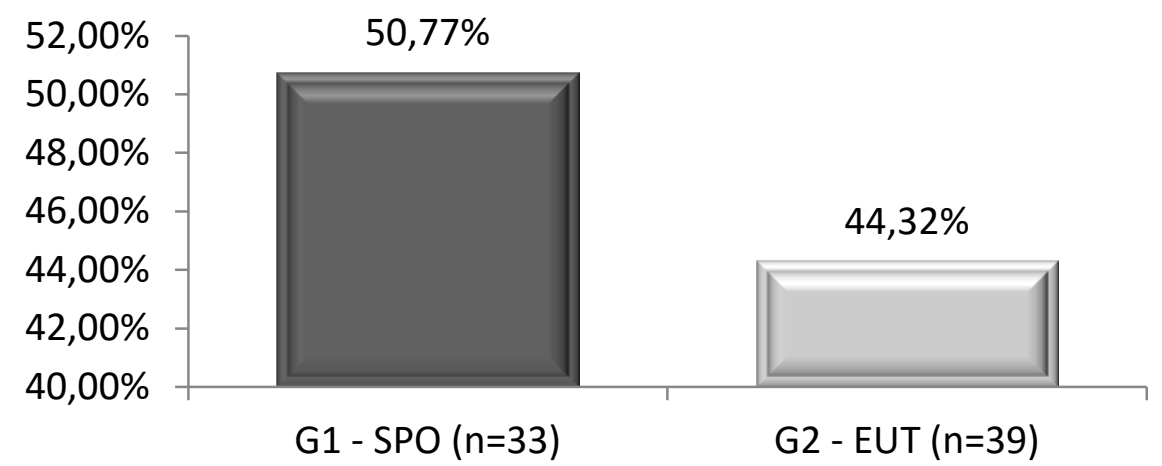

Gráfico 3 - Porcentagem de adolescentes livres de cárie observada nos dois grupos

O índice CPOD geral na amostra estudada foi de 1,53, sendo observado 1,28 $\pm 1,60$ em G1 e 1,73 $\pm 2,30$ em G2. Observou-se ausência de dentes perdidos em ambos os grupos, sendo que o componente restaurado teve maior contribuição na média do CPOD em relação aos outros. O índice significativo de cárie (SIC index) foi de 3,18 $\pm 1,18$ para G1 e de 4,28 para G2 $\pm 2,33$ (Tabela 2).

Tabela 2 - Distribuição da cárie dentária nos adolescentes com SPO (G1) e EUT (G2)

\begin{tabular}{cccccc}
\hline & Cariado & Perdido & Restaurado & CPOD & SIC Index \\
\hline G1 & 0,48 & 0,00 & 0,80 & 1,28 & 3,18 \\
G2 & 0,80 & 0,00 & 0,93 & 1,73 & 4,28 \\
\hline
\end{tabular}


Quando comparados os grupos em relação ao CPOD, não foram encontradas diferenças estatisticamente significativas $(p>0,05)$ (Tabelas 3 e 4).

Tabela 3 - Índice CPOD e comparação entre os grupos SPO (G1) e EUT (G2)

\begin{tabular}{cccc}
\hline Condição & G1 & G1 & M \\
& Média (dp) & Média (dp) & \\
\hline CPOD & $1,28(1,60)$ & $1,73(2,30)$ & 0,367 \\
\hline
\end{tabular}

$p<0,05 \%$

Tabela 4 - Associação entre cárie dentária e IMC nos adolescentes com SPO (G1) e EUT (G2)

\begin{tabular}{|c|c|c|c|c|c|c|}
\hline \multirow{2}{*}{\multicolumn{2}{|c|}{ Condição }} & \multicolumn{2}{|c|}{ IMC } & \multirow{2}{*}{ OR } & \multirow{2}{*}{ IC 95\% } & \multirow{2}{*}{$p$} \\
\hline & & G1 & G2 & & & \\
\hline \multirow{2}{*}{ CPOD } & 0 & 32 & 49 & \multirow{2}{*}{0,642} & 0,405 & \multirow{2}{*}{0,429} \\
\hline & $>0$ & 33 & 39 & & 1,468 & \\
\hline \multirow{2}{*}{ Cariados } & 0 & 47 & 56 & \multirow{2}{*}{0,695} & 0,334- & \multirow{2}{*}{0,258} \\
\hline & $>0$ & 18 & 32 & & 1,343 & \\
\hline
\end{tabular}

$p<0,05 \%$

\subsubsection{Fluorose dentária}

No geral, foi observada a presença de fluorose em 18,30\% dos adolescentes, sendo que em G1 verificou-se 23,08\% e em G2 14,77\% (Gráfico 4).

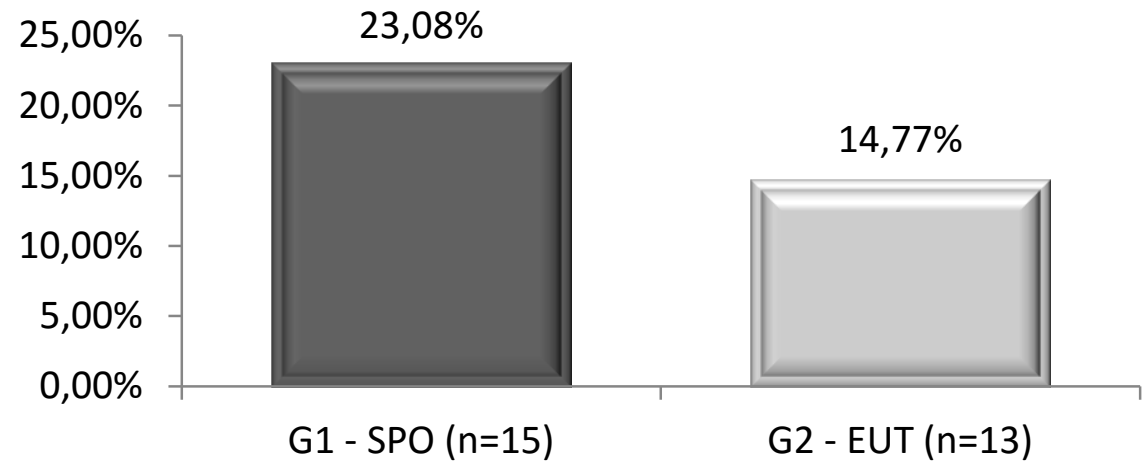

Gráfico 4 - Porcentagem de adolescentes com fluorose observada nos dois grupos 
Revelou-se que, com relação à severidade, a condição normal de fluorose foi a mais frequente (Gráfico 5).

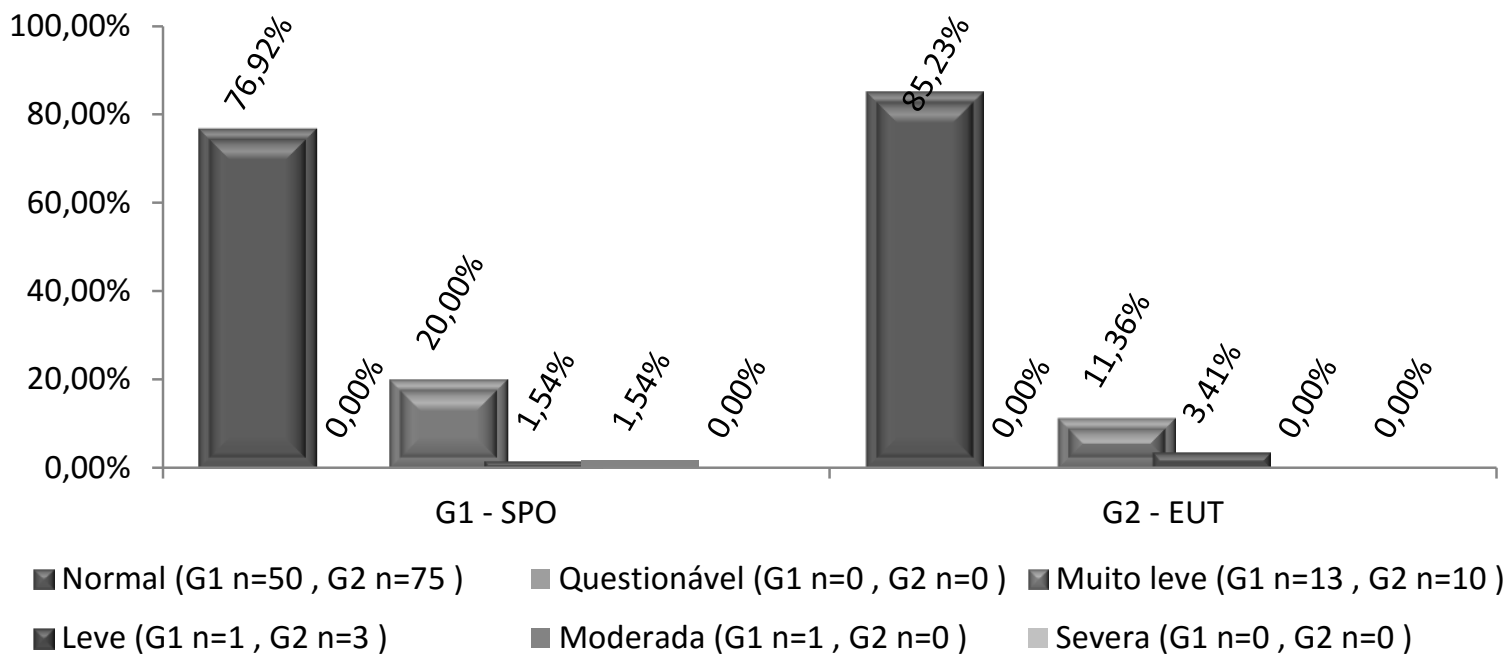

Gráfico 5 - Frequência em ambos os grupos, em função da severidade da fluorose dentária (em \%)

Quando comparados os grupos em relação a fluorose dentária, não foram encontradas diferenças estatisticamente significativas $(p>0,05)$ (Tabela 5).

Tabela 5 - Associação entre a Fluorose dentária e IMC nos adolescentes com SPO (G1) e EUT (G2)

\begin{tabular}{ccccccc}
\hline \multirow{2}{*}{ Condição } & & \multicolumn{2}{c}{ IMC } & OR & IC 95\% & p \\
& & G1 & G2 & & & \\
\hline \multirow{2}{*}{ Fluorose dentária } & Sim & 15 & 13 & 0,824 & $3,758-$ & 0,189 \\
& Não & 50 & 75 & & 3,947 & \\
\hline
\end{tabular}

$\mathrm{p}<0,05 \%$

Em relação ao Índice de fluorose comunitária, foi encontrado o valor de 0,22 para a amostra total, e com relação aos grupos, 0,28 para G1 e 0,18 para G2 (Gráfico 6) 


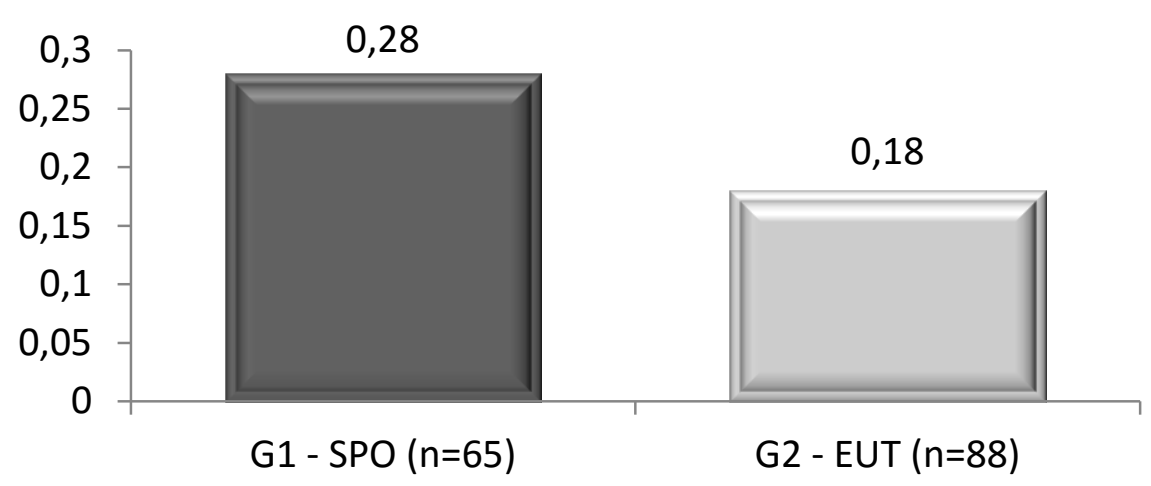

Gráfico 6 - Índice de fluorose comunitário observado nos dois grupos

\subsubsection{Condição periodontal}

Observou-se que a prevalência de alterações periodontais foi de 52,31\% dos adolescentes no G1, e 65,91\% no G2 (Gráfico 7).

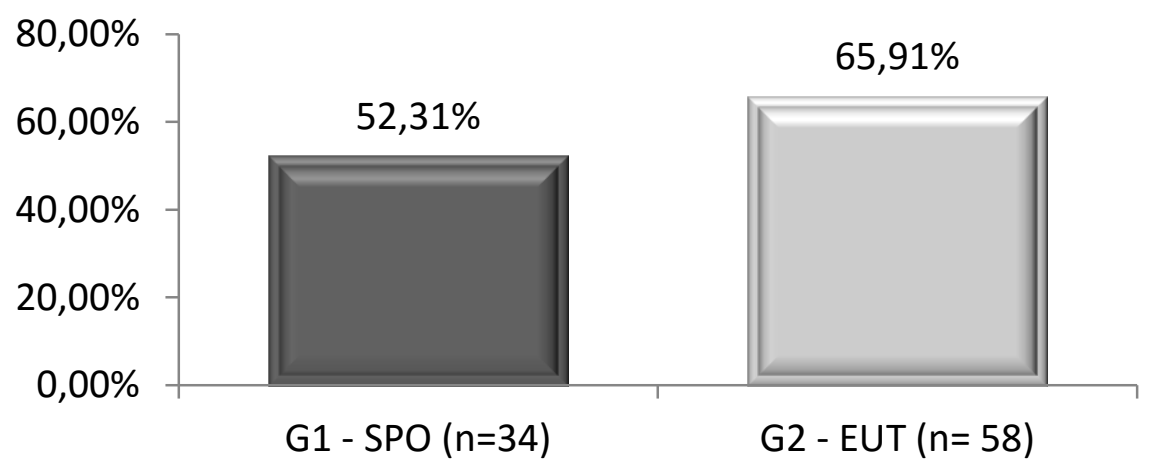

Gráfico 7 - Porcentagem de adolescentes que apresentaram alterações periodontais

Sangramento gengival foi observado de modo semelhante em ambos os grupos, sendo de 47,69\% em G1, e de 47,73\% em G2. Em relação à presença de cálculo dentário, este esteve presente em 29,23\% no G1, e 44,32\% no G2 (Tabela $6)$.

Quando comparados os grupos em relação à associação entre o sangramento gengival e o cálculo dentário, não foram encontradas diferenças estatisticamente significativas $(p>0,05)$ (Tabela 7$)$. 
Tabela 6 - Presença de sangramento gengival e cálculo dentário nos adolescentes com SPO (G1) e EUT (G2)

\begin{tabular}{ccccccc}
\hline Condição & & \multicolumn{2}{c}{ G1 } & \multicolumn{2}{c}{ G2 } \\
& & $\mathrm{n}$ & $\%$ & $\mathrm{n}$ & $\%$ \\
\hline \multirow{2}{*}{ Sangramento gengival } & Sim & 31 & 47,69 & 42 & 47,73 \\
& Não & 34 & 52,31 & 46 & 52,27 \\
\multirow{2}{*}{ Cálculo dentário } & Sim & 19 & 29,23 & 39 & 44,32 \\
& Não & 46 & 70,77 & 49 & 55,68 \\
\hline
\end{tabular}

Tabela 7 - Associação entre condições periodontais e IMC nos adolescentes com SPO (G1) e EUT (G2)

\begin{tabular}{cccccccc}
\hline \multirow{2}{*}{ Condição } & \multicolumn{3}{c}{ IMC } & OR & IC 95\% & p \\
& & G1 & G2 & & & \\
\hline \multirow{2}{*}{ Sangramento gengival } & Sim & 31 & 42 & \multirow{2}{*}{0,641} & $0,525-$ & \multirow{2}{*}{0,997} \\
& Não & 34 & 46 & & 1,897 & \\
\multirow{2}{*}{ Cálculo dentário } & Sim & 19 & 39 & \multirow{2}{*}{0,680} & $0,262-$ & \multirow{2}{*}{0,057} \\
& Não & 46 & 49 & & 1,024 & \\
\hline
\end{tabular}

$\mathrm{p}<0,05 \%$

\subsubsection{Desgaste dentário}

Todos os adolescentes avaliados, tanto em G1 como G2, apresentaram desgaste dentário em pelo menos um elemento dentário. A face mais acometida pelo desgaste dentário, em ambos os grupos, foi a incisal/oclusal (Tabela 8).

Dentre os grupos de dentes mais acometidos pelo desgaste dentário estiveram os incisivos (G1 97,88\%; G2 97,02\%) e os pré-molares (G1 76,15\%; G2 74,43\%) (Gráfico 8). 
Tabela 8 - Prevalência de desgaste dentário por faces nos adolescentes com SPO (G1) e EUT (G2)

\begin{tabular}{|c|c|c|c|c|c|c|}
\hline \multicolumn{2}{|c|}{ Grupo } & Sem & Vestibular & Incisal/Oclusal & Lingual & Faces avaliadas \\
\hline \multirow{2}{*}{ G1 } & $\mathrm{n}$ & 3248 & 32 & 1445 & 6 & 4731 \\
\hline & $\%$ & 68,65 & 0,68 & 30,54 & 0,13 & 100,00 \\
\hline \multirow{2}{*}{ G2 } & $\mathrm{n}$ & 4289 & 48 & 1902 & 18 & 6257 \\
\hline & $\%$ & 68,55 & 0,77 & 30,40 & 0,29 & 100,00 \\
\hline
\end{tabular}

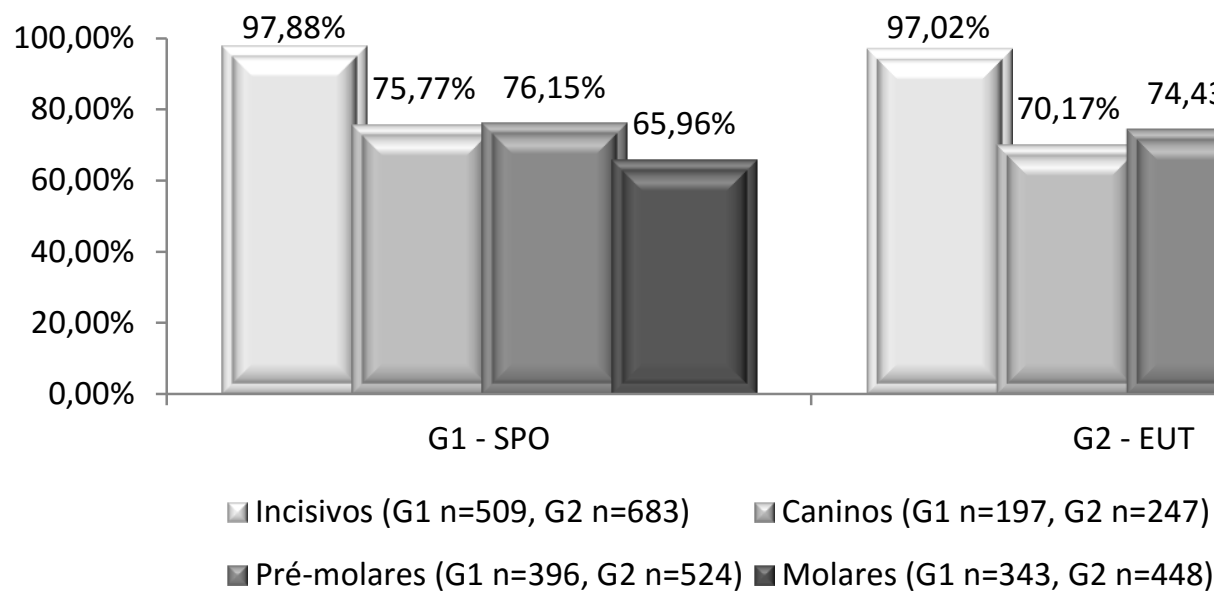

Gráfico 8 - Prevalência de desgaste dentário por grupos de dentes nos adolescentes com SPO (G1) e EUT (G2)

Em relação à severidade do desgaste nos diferentes grupos dentários, observou-se que esteve mais presente no esmalte dentário (Incipiente) (Tabela 9).

Tabela 9 - Severidade do desgaste dentário por grupos de dentes nos adolescentes com SPO (G1) e EUT (G2)

\begin{tabular}{ccccccccc}
\hline \multirow{2}{*}{ Severidade } & \multicolumn{2}{c}{ Incisivos } & \multicolumn{2}{c}{ Caninos } & \multicolumn{2}{c}{ Pré-molares } & \multicolumn{2}{c}{ Molares } \\
& G1 (\%) & G2 (\%) & G1 (\%) & G2 (\%) & G1 (\%) & G2 (\%) & G1 (\%) & G2 (\%) \\
\hline Normal & 2,12 & 2,98 & 24,23 & 29,83 & 23,85 & 25,57 & 34,04 & 36,36 \\
Incipiente & 90,19 & 88,35 & 56,92 & 56,25 & 68,46 & 69,46 & 57,50 & 59,66 \\
Moderado & 7,69 & 8,52 & 18,85 & 13,92 & 7,69 & 4,97 & 8,46 & 3,98 \\
Severo & 0,00 & 0,00 & 0,00 & 0,00 & 0,00 & 0,00 & 0,00 & 0,00 \\
Restaurado & 0,00 & 0,14 & 0,00 & 0,00 & 0,00 & 0,00 & 0,00 & 0,00 \\
\hline
\end{tabular}


A associação entre a severidade do desgaste dentário e o IMC foi evidenciada entre os adolescentes avaliados $(p<0,05)$ (Tabela 10).

Tabela 10 - Associação entre desgaste dentário e IMC nos adolescentes com SPO (G1) e EUT (G2)

\begin{tabular}{|c|c|c|c|c|c|c|}
\hline \multirow{2}{*}{ Condição } & & \multicolumn{2}{|c|}{ IMC } & \multirow{2}{*}{ OR } & \multirow{2}{*}{ IC 95\% } & \multirow{2}{*}{$p$} \\
\hline & & G1 & G2 & & & \\
\hline \multirow{2}{*}{ Desgaste Dentário } & Esmalte & 21 & 44 & \multirow{2}{*}{0,666} & $0,245-$ & \multirow{2}{*}{$0,029^{*}$} \\
\hline & Dentina & 44 & 44 & & 0,929 & \\
\hline
\end{tabular}

$\mathrm{p}<0,05 \%$

\subsubsection{Má oclusão dentária}

Os adolescentes avaliados apresentaram alta prevalência de má oclusão, sendo observado sem anormalidades/oclusopatias leves em apenas 29,23\% em G1 e 22,73\% em G2 (Gráfico 9).

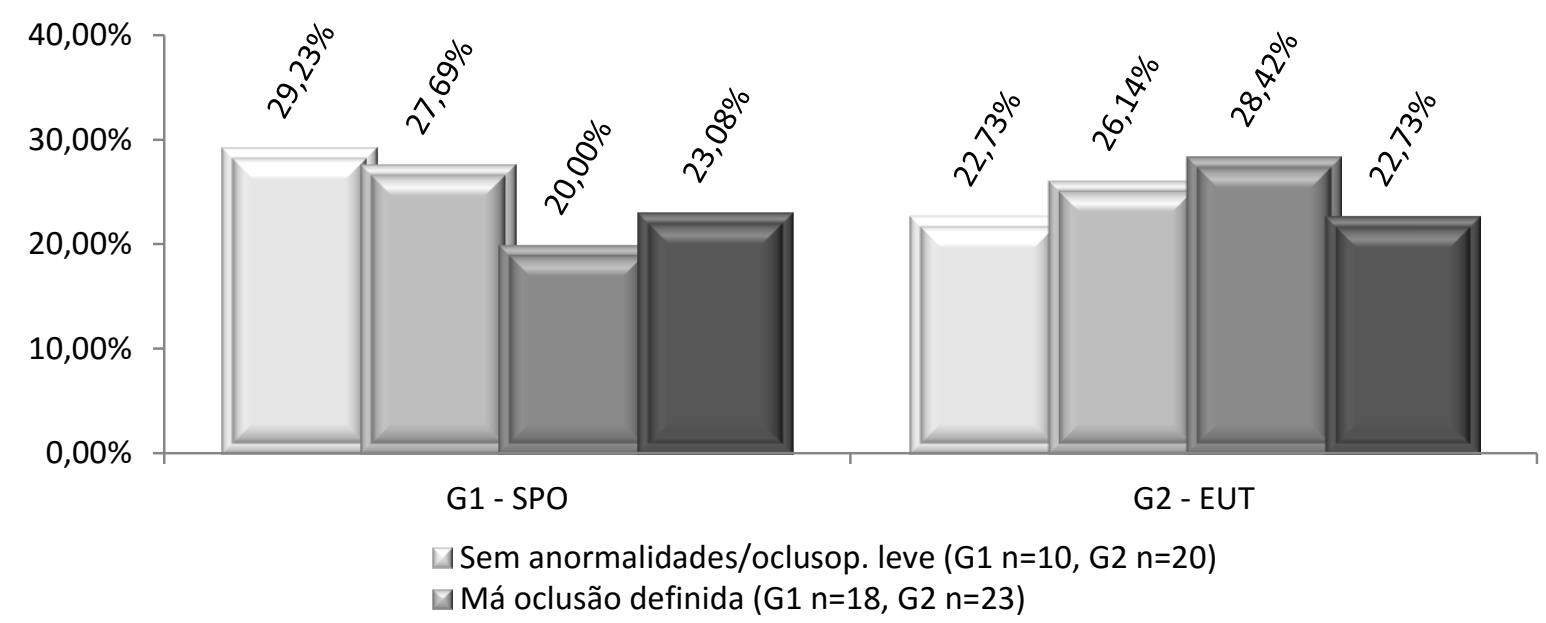

Gráfico 9 - Frequência em função da severidade da má oclusão dentária (em \%) entre os grupos SPO (G1) e EUT (G2)

A média de DAl obtido em G1 foi de 31,69 e em G2 30,46, não sendo observadas diferenças significativas entre os grupos $(p>0,05)$ (Tabelas 11 e 12). 
Tabela 11 - Índice DAl e comparação entre os grupos SPO (G1) e EUT (G2)

\begin{tabular}{cccc}
\hline Condição & $\begin{array}{c}\text { G1 } \\
\text { Média (dp) }\end{array}$ & $\begin{array}{c}\text { G1 } \\
\text { Média (dp) }\end{array}$ & $\boldsymbol{p}$ \\
\hline DAl & $31,69(7,93)$ & $30,46(7,40)$ & 0,383 \\
\hline
\end{tabular}

$\mathrm{p}<0,05 \%$

Tabela 12 - Associação entre DAI e IMC nos adolescentes com SPO (G1) e EUT (G2)

\begin{tabular}{ccccccc}
\hline \multirow{2}{*}{ Condição } & \multicolumn{2}{c}{ IMC } & \multirow{2}{*}{ OR } & IC 95\% & \multirow{2}{*}{} \\
& S1 & G2 & & & \\
\hline \multirow{2}{*}{ DAI } & Sem MO/Leve & 19 & 20 & \multirow{2}{*}{0,730} & $0,342-$ & \multirow{2}{*}{0,363} \\
& MO Severa/Muito severa & 46 & 68 & & 1,479 & \\
\hline
\end{tabular}

$p<0,05 \%$

\subsubsection{Fluxo salivar}

A média geral do fluxo salivar dos adolescentes foi $0,75 \mathrm{ml} / \mathrm{min}$, apresentando-se de forma muito semelhante em ambos os grupos. (Gráfico 10). Revelou-se que, independente do grupo, a hipossalivação foi a condição mais frequente (Gráfico 11).

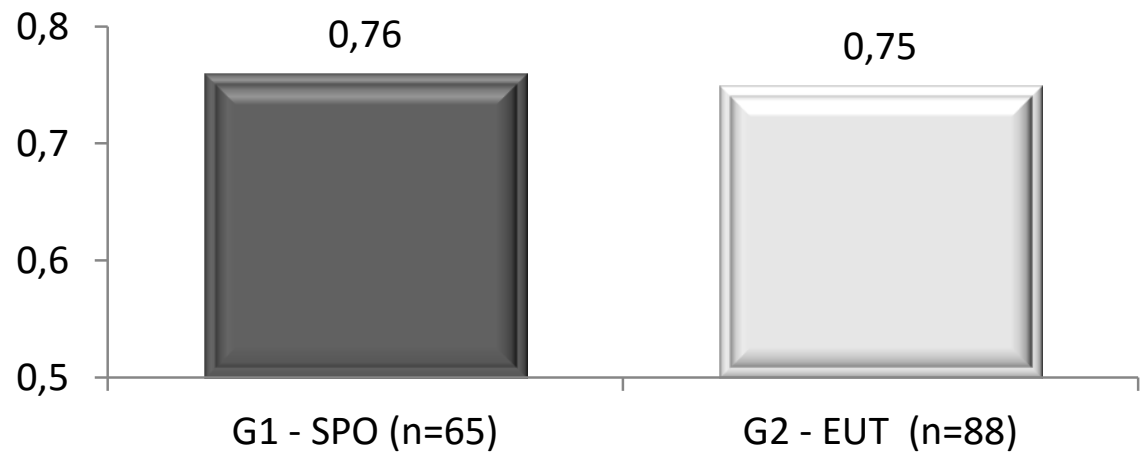

Gráfico 10 - Médias do fluxo salivar (em $\mathrm{ml} / \mathrm{min}$ ) observadas nos dois grupos 


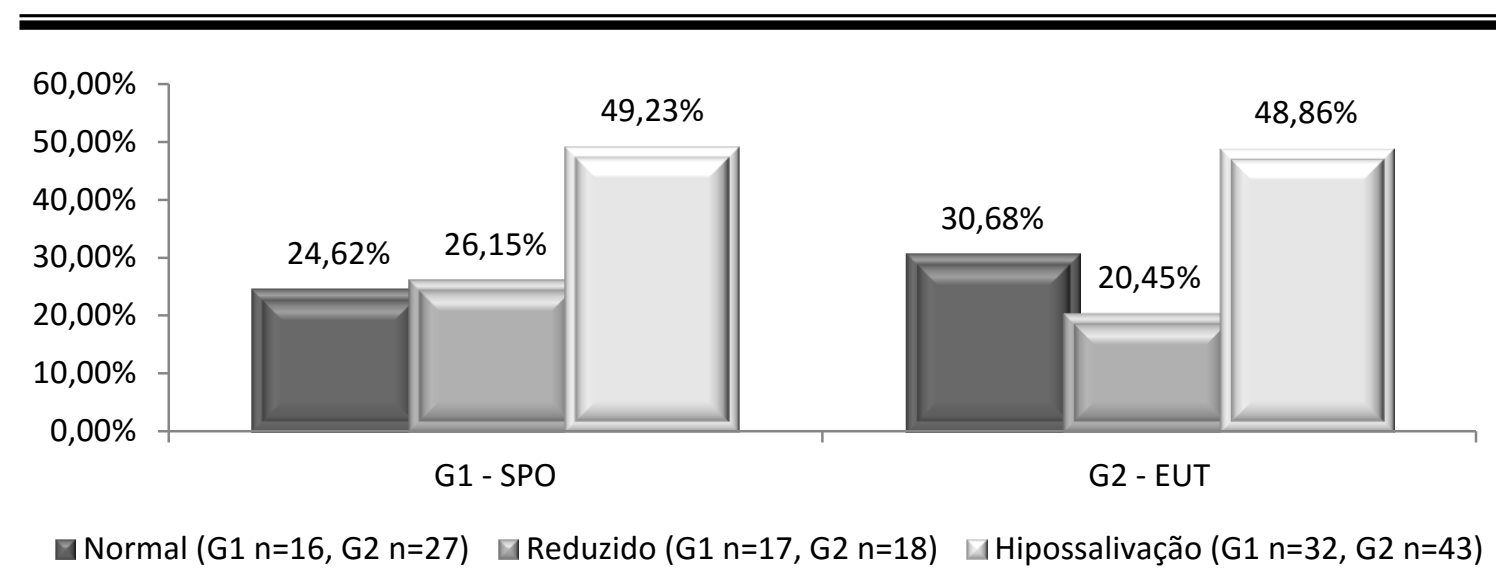

Gráfico 11 - Frequência em ambos os grupos em função da condição de salivação (em \%)

Quando comparados os grupos em relação ao fluxo salivar, não foram encontradas diferenças estatisticamente significativas $(p>0,05)$ (Tabelas 13 e 14).

Tabela 13 - Fluxo salivar (ml/min) e comparação entre os grupos SPO (G1) e EUT (G2)

\begin{tabular}{cccc}
\hline Condição & $\begin{array}{c}\text { G1 } \\
\text { Média (dp) }\end{array}$ & $\begin{array}{c}\text { G2 } \\
\text { Média (dp) }\end{array}$ & $\boldsymbol{p}$ \\
\hline Fluxo Salivar & $0,76(0,43)$ & $0,75(0,39)$ & 0,450 \\
\hline
\end{tabular}

$\mathrm{p}<0,05 \%$

Tabela 14 - Associação entre Fluxo salivar e IMC nos adolescentes com SPO (G1) e EUT (G2)

\begin{tabular}{lcccccc}
\hline \multirow{2}{*}{ Condição } & \multicolumn{2}{c}{ IMC } & \multirow{2}{*}{ OR } & IC 95\% & \multirow{2}{*}{$\boldsymbol{p}$} \\
& & G1 & G2 & & & \\
\hline \multirow{2}{*}{ Fluxo Salivar } & Normal & 32 & 49 & \multirow{2}{*}{0,723} & $0,657-$ & \multirow{2}{*}{0,409} \\
& Red./Hip. & 33 & 39 & & 2,795 & \\
\hline
\end{tabular}

$\mathrm{p}<0,05 \%$

5.3 QUESTIONÁRIO SOBRE O IMPACTO DAS ATIVIDADES DIÁRIAS NA QUALIDADE DE VIDA 
A aplicação do questionário CHILD-OIDP foi realizada em duas etapas, sendo a primeira constituída pelo relato das condições bucais percebidas pelos adolescentes, e a segunda constituída pelo impacto destas condições nas atividades diárias.

Na primeira etapa as condições bucais mais relatadas pelos adolescentes foram dentes sensíveis $(72,31 \%$ G1; $69,32 \%$ G2), posição dentária $(66,15 \%$ G1; $53,41 \%$ G2) e cor dos dentes (66,15\% G1; 52,27\% G2) (Tabela 15).

Tabela 15 - Condições bucais percebidas pelos adolescentes com SPO (G1) e EUT (G2)

\begin{tabular}{cccccc}
\hline Condições Bucais & \multicolumn{2}{c}{ G1 } & \multicolumn{3}{c}{ G2 } \\
& $\mathbf{n}$ & $\%$ & N & $\%$ \\
\hline Dor de dente & 22 & 33,85 & 31 & 35,23 \\
Dentes sensíveis & 47 & 72,31 & 61 & 69,32 \\
Cárie & 10 & 15,38 & 22 & 25,00 \\
Dente de leite mole & 15 & 23,08 & 29 & 32,95 \\
Espaços & 22 & 33,85 & 28 & 31,82 \\
Dente permanente quebrado & 4 & 6,15 & 6 & 6,82 \\
Cor dos dentes & 43 & 66,15 & 46 & 52,27 \\
Forma e tamanho & 25 & 38,46 & 31 & 35,23 \\
Posição & 43 & 66,15 & 47 & 53,41 \\
Sangramento & 22 & 33,85 & 33 & 37,50 \\
Gengiva inchada & 12 & 18,46 & 12 & 13,64 \\
Tártaro & 15 & 23,08 & 18 & 20,45 \\
Feridas & 19 & 29,23 & 26 & 29,55 \\
Mau hálito & 31 & 47,69 & 44 & 50,00 \\
Deformidades & 0 & 0,00 & 1 & 1,14 \\
Dente permanente irrompendo & 33 & 50,77 & 40 & 45,45 \\
Dente permanente perdido & 0 & 0,00 & 0 & 0,00 \\
\hline
\end{tabular}

Após a segunda etapa do questionário, os escores médios obtidos pelos grupos foram 6,94 para G1 e 5,35 para G2, não havendo diferenças significativas entre os grupos $(p>0,05)$ (Tabela 16). 
Com relação ao impacto das condições bucais nas atividades diárias dos adolescentes, em G1 observou-se prevalência moderada em comer, estado emocional e sorrir; enquanto em G2 observou-se impacto moderado em sorrir e pequeno em comer e higienização bucal (Tabela 17).

Tabela 16 - Escores médios do CHILD-OIDP obtidos pelos adolescentes com SPO (G1) e EUT (G2)

\begin{tabular}{cccc}
\hline Condição & $\begin{array}{c}\text { G1 } \\
\text { Média (dp) }\end{array}$ & $\begin{array}{c}\text { G2 } \\
\text { Média (dp) }\end{array}$ & $\boldsymbol{p}$ \\
\hline CHILD-OIDP & $6,94(9,38)$ & $5,35(6,84)$ & 0,958
\end{tabular}

$p<0,05 \%$

Tabela 17 - Impacto das condições bucais percebidas nas atividades diárias dos adolescentes com SPO (G1) e EUT (G2)

\begin{tabular}{|c|c|c|c|c|c|c|c|c|c|}
\hline & & 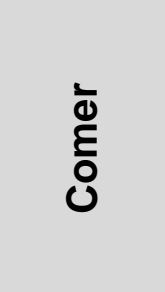 & $\frac{\frac{\pi}{\sigma}}{\leftarrow}$ & 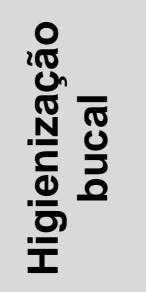 & 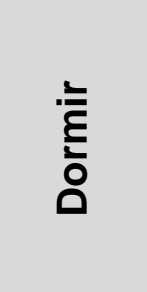 & 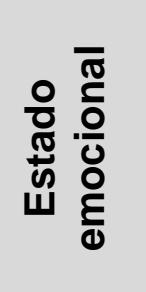 & $\begin{array}{l}\text { के } \\
\text { கे }\end{array}$ & 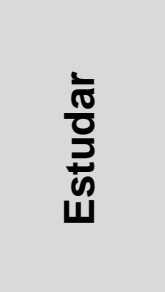 & $\begin{array}{l}\frac{0}{0} \\
\frac{\pi}{\pi} \\
\frac{\pi}{0} \\
0 \\
0\end{array}$ \\
\hline & & $\%$ & $\%$ & $\%$ & $\%$ & $\%$ & $\%$ & $\%$ & $\%$ \\
\hline \multirow{7}{*}{ G1 } & Muito severo & 0,00 & 0,00 & 3,08 & 0,00 & 4,62 & 9,23 & 0,00 & 1,54 \\
\hline & Severo & 9,23 & 4,62 & 3,08 & 1,54 & 3,08 & 1,54 & 0,00 & 0,00 \\
\hline & Moderado & 10,77 & 0,00 & 7,69 & 0,00 & 10,77 & 9,23 & 0,00 & 1,54 \\
\hline & Pequeno & 9,23 & 4,62 & 4,62 & 1,54 & 3,08 & 1,54 & 0,00 & 1,54 \\
\hline & Muito pequeno & 3,08 & 3,08 & 4,62 & 1,54 & 3,08 & 0,00 & 0,00 & 1,54 \\
\hline & Sem impacto & 67,69 & 87,69 & 76,92 & 95,38 & 75,38 & 78,46 & 100,00 & 93,85 \\
\hline & Total & 100,00 & 100,00 & 100,00 & 100,00 & 100,00 & 100,00 & 100,00 & 100,00 \\
\hline \multirow{7}{*}{ G2 } & Muito severo & 2,27 & 0,00 & 4,55 & 0,00 & 2,27 & 2,27 & 0,00 & 1,14 \\
\hline & Severo & 3,41 & 1,14 & 3,41 & 0,00 & 2,27 & 3,41 & 0,00 & 0,00 \\
\hline & Moderado & 3,41 & 0,00 & 1,14 & 0,00 & 5,68 & 6,82 & 0,00 & 0,00 \\
\hline & Pequeno & 14,77 & 3,41 & 6,82 & 0,00 & 6,82 & 4,55 & 1,14 & 0,00 \\
\hline & Muito pequeno & 6,82 & 0,00 & 6,82 & 2,27 & 5,68 & 3,41 & 1,14 & 2,27 \\
\hline & Sem impacto & 69,32 & 95,45 & 77,27 & 97,73 & 77,27 & 79,55 & 97,73 & 96,59 \\
\hline & Total & 100,00 & 100,00 & 100,00 & 100,00 & 100,00 & 100,00 & 100,00 & 100,00 \\
\hline
\end{tabular}


Os adolescentes em ambos os grupos apresentaram frequência de impacto nas atividades diária de forma semelhante, não havendo relação significativa a presença de impacto e IMC $(p>0,05)$ (Tabela 18).

Tabela 18 - Associação entre o impacto nas atividades diárias e o IMC nos adolescentes com SPO (G1) e EUT (G2)

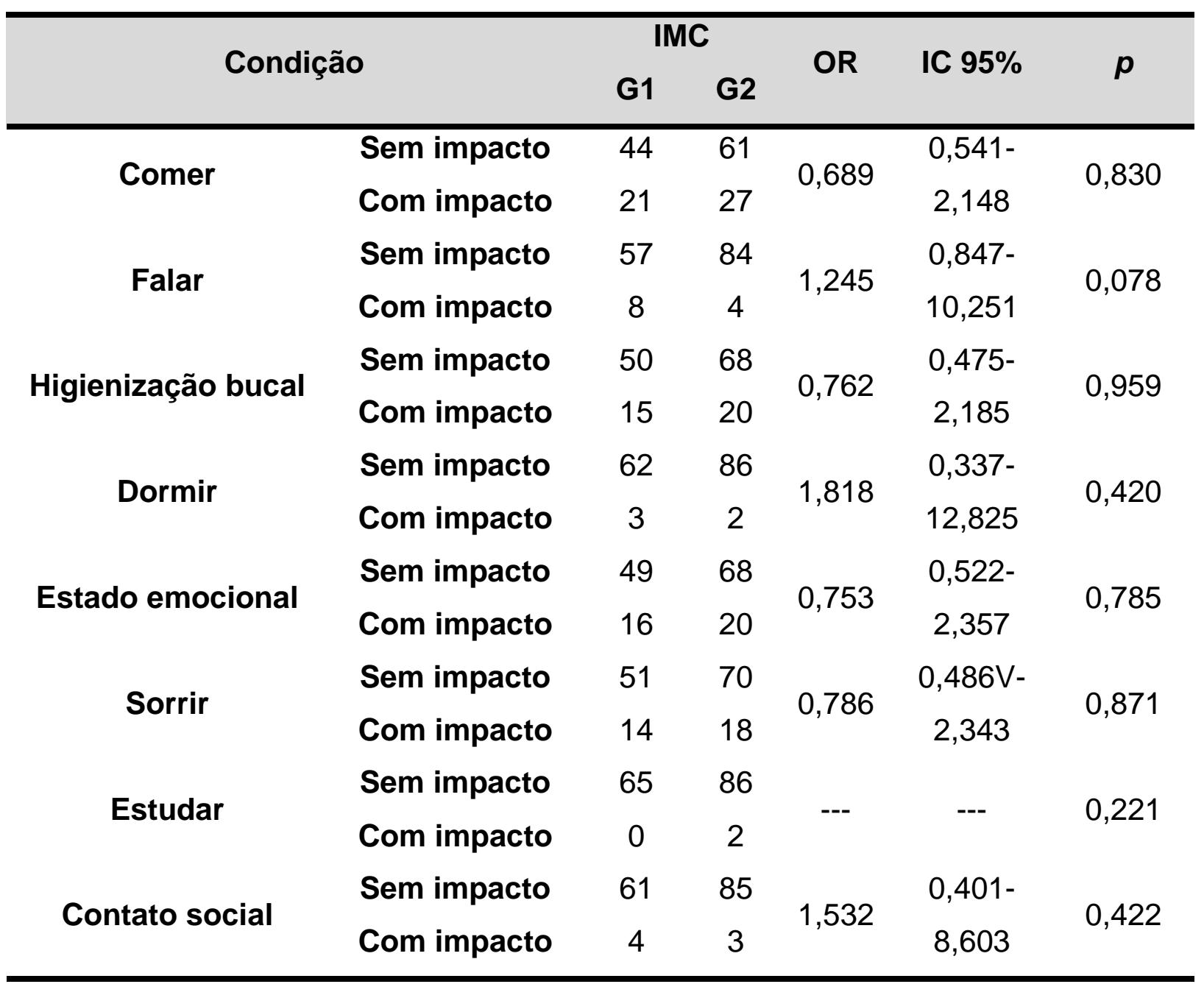

$p<0,05 \%$

Em G1, observou-se correlação negativa estatisticamente significante entre os escores do CHILD-OIDP e o fluxo salivar ( $r=-0,263 ; p<0,05)$. No G2 não foram observadas correlações entre as condições bucais e o CHILD-OIDP $(p>0,05)$ (Tabela 19). 
Tabela 19 - Correlação Linear de Pearson entre CHILD-OIDP e condições bucais entre os adolescentes com SPO (G1) e EUT (G2)

\begin{tabular}{cccccc}
\hline Condição & \multicolumn{2}{c}{$\mathbf{G 1}$} & \multicolumn{2}{c}{$\mathbf{G 2}$} \\
& $\mathbf{r}$ & $\boldsymbol{p}$ & $\mathbf{r}$ & $\boldsymbol{p}$ \\
\hline CPOD & $-0,132$ & 0,292 & 0,029 & 0,783 \\
DAl & 0,053 & 0,672 & 0,032 & 0,766 \\
Fluxo salivar & $-0,263$ & $0,034^{\star}$ & 0,189 & 0,076 \\
\hline
\end{tabular}

$\mathrm{p}<0,05 \%$ 


\section{Discussão}



6 DISCUSSÃO

A obesidade é uma condição médica na qual o excesso de gordura corporal acumulado pode desencadear efeitos adversos ao indivíduo, levando à redução da expectativa de vida e/ou aumento dos agravos à saúde (WHO, 2015). Em todo o mundo, esta condição tem sido observada com mais frequência em crianças (CATTANEO et al., 2010), sendo considerado um problema de saúde pública, uma vez que as crianças que apresentam sobrepeso poderão tornar-se adultos com excesso de peso (GUO \& CHUMLEA, 1999). Tendo em vista o aumento na prevalência da obesidade, torna-se necessária a avaliação e a atenção integral à saúde dos indivíduos, bem como o seu acompanhamento por equipes multiprofissionais, a fim de se melhorar a qualidade de vida.

Pelo fato de haver uma ação sinérgica entre nutrição e saúde bucal (TOUGER-DECKER \& MOBLEY, 2007), o levantamento de dados a partir de estudos epidemiológicos realizados na odontologia é fundamental para a avaliação das necessidades dos vários grupos etários, proporcionando uma melhor organização do atendimento com programações específicas para a promoção da saúde bucal (ANTUNES \& PERES, 2006). No entanto, ainda são poucos os trabalhos encontrados na literatura mundial correlacionado a saúde bucal de adolescentes com a sua condição nutricional. Deste modo, o presente estudo objetivou analisar a relação entre as condições bucais e o estado nutricional em adolescentes aos 12 anos de idade.

\subsection{ANÁLISE ANTROPOMÉTRICA}

Os índices antropométricos em adolescentes servem para avaliar o seu crescimento e, indiretamente, para caracterizar o estado nutricional da População (ANJOS, 1988). Neste estudo, utilizou-se o Índice de Massa Corporal (IMC), que embora apresente em adolescentes importante variação com a idade e com a maturidade sexual, tem sido considerado como bom indicador de obesidade em adolescentes (SALES-PERES et al., 2010). Isto se deve à sua facilidade de realização, objetividade da medida e possibilidade de comparação com um padrão 
de referência de manuseio relativamente simples, principalmente em estudos populacionais (DOUEK \& LEONE, 1995).

No presente estudo, observou-se que $40,52 \%$ dos adolescentes avaliados apresentavam SPO; e na observação por gênero, $51,14 \%$ do feminino e $30,76 \%$ do masculino se enquadravam nesta condição. Quando comparados aos valores obtidos pela Pesquisa de Orçamento Familiar (POF) (Brasil, 2010), realizado em todo o país e estratificado na idade de 12 e 13 anos, observou-se uma maior prevalência de SPO em nossa amostra, visto que a POF encontrou $31,20 \%$ de adolescentes nesta condição. Ainda, no POF encontrou-se discrepância também na análise por gênero, pois os meninos $(36,9 \%)$ demonstram-se mais propensos ao SPO que as mulheres $(24,9 \%)$.

\subsection{CONDIÇÃO BUCAL}

A quantidade total de adolescentes que se apresentaram livres de cárie (47,05\%) demonstrou-se superior ao encontrado no SB Brasil 2010 (43,50\%), sendo porém semelhante ao resultados obtidos quando estratificado somente a região Sudeste do País (48,40\%). O grupo SPO $(50,77 \%)$ apresentou-se com uma maior porcentagem de adolescentes nesta condição quando comparado com os EUT $(44,32 \%)$, entretanto sem diferenças significativas. O índice CPOD geral na amostra estudada foi de 1,53 , abaixo no observado em âmbito nacional $(2,07)$ e da região Sudeste (1,72). Freire et al., em 2013, observaram um índice CPOD de 1,74 em adolescentes aos 12 anos moradores de cidades do interior dos estados da região Sudeste, trabalhando com dados do SBBrasil 2010; enquanto Freitas et al., em 2014, em estudo realizado na cidade de Dois Córregos, interior do estado de São Paulo, observaram que adolescentes aos 12 anos de idade com sobrepeso/obesidade apresentavam-se com um índice CPOD menor (1.67) quando comparados com adolescentes Eutróficos (2.12), havendo significante correlação estatística entre a condição antropométrica e a presença de cárie. No município de Bauru, onde se encontrava a amostra deste estudo, o declínio da cárie dentária se deu a partir do início da fluoretação da água de abastecimento público, em 1976 (BRASIL, 1976). Isto ficou evidente com a potencialização deste declínio a partir dos levantamentos realizados em 1990 e 1994/1995 (BASTOS, 2001). O grupo EUT 
$(1,73)$ apresentou-se com um CPOD maior quando comparado com os SPO $(1,28)$ apesar de estatisticamente não haver diferenças, estando de acordo com outros trabalhos na literatura que objetivaram realizar análise semelhante com adolescentes (MARSHALL et al., 2007; TRIPATHI et al., 2010; MOREIRA, 2003; CRISPIM et al., 2010; TAMBELINI et al., 2010; TONG et al., 2013). Alguns autores apontaram que a prevalência da cárie diminui à medida que melhora a condição socioeconômica, mesmo em áreas sem a adição de flúor à agua de abastecimento público (JONES \& WORTHINGTON, 2000; MARCENES \& BONECKER, 2000). Segundo Freire et al., em 2013, apesar do declínio da cárie em todo o Brasil, observa-se que a mesma ainda é mais prevalente em crianças submetidas à privação material. Visto que a amostra deste estudo foi coletada apenas em escolas públicas, pode-se aventar a possibilidade dos adolescentes com SPO possuírem maiores acesso a alimentos industrializados do que os adolescentes EUT, havendo uma possível correlação socioeconômica. Para Goodson et al., em 2013, que observaram que a porcentagem de adolescentes com dentes cariados ou restaurados variou inversamente com a classificação antropométrica; a observação de uma relação inversa entre obesidade e cárie dental, contradiz as hipóteses de relação entre açúcar e obesidade e a relação entre obesidade e cárie dental. Para os autores, as razões para esta relação inversa não estão claras, pois o açúcar é aceito como presença necessária para a cárie dental, e como um dos cofatores principais para a obesidade. Se estas hipóteses fossem verdadeiras, seria de esperar que a cárie dentária aumentasse com a obesidade.

O índice significativo de cárie (SIC index) encontrado no geral foi 3,80, quase 2,5 vezes superior ao valor do CPOD geral, demonstrando uma polarização da cárie dentária com elevada concentração da doença em menor percentual de grupo populacional. O grupo EUT $(4,28)$ apresentou um SIC mais elevado quando comparado com SPO $(3,18)$. Estes resultados corroboram com o estudo de Freitas et al., que em 2014 observaram que adolescentes aos 12 anos de idade com sobrepeso/obesidade apresentavam-se um SIC index menor (3.85) quando comparados com adolescentes Eutróficos (4.26); havendo significante correlação estatística entre a condição antropométrica e este índice. Este dado demonstra-se de extrema importância, pois a identificação dos grupos polarizados torna-se 
fundamental para direcionar ações em saúde bucal pelo serviço público de saúde, reduzindo-se assim desigualdades nas condições de saúde bucal.

Com relação à fluorose dentária, neste estudo foi observado que 18,30\% dos adolescentes estavam acometidos pela mesma, principalmente na condição de fluorose muito leve. Este dado apresentou-se semelhante a outros achados da literatura tendo adolescentes como amostra: 14,64\% em Brasília - DF, 16,83\% em Salvador - BA, e 16,20\% em Maringá - PR (CAMPOS et al., 1998; TERADA et al., 2009; OLIVEIRA-JUNIOR et al., 2006, FREITAS et al., 2013). Freitas et al., em 2013, utilizando dados do SBBrasil 2003 e SBBrasil 2010, observaram respectivamente, prevalência de fluorose de $7,40 \%$ e $16,7 \%$. Isto corrobora com o observado contemporaneamente, onde se têm uma tendência inversa da fluorose em relação à cárie dentária, especialmente nas formas muito leve e leve (SALIBA et al., 2006). Na presente pesquisa, apesar de estatisticamente não haver diferença, os adolescente com SPO (23,08\%) a apresentaram com frequência nitidamente maior quando comparado com os EUT (14,77\%), contribuindo assim decisivamente com a porcentagem total já apresentada. Este fato deve-se talvez pela ingestão maior de alimentos e bebidas industrializadas nos adolescente do G1, o que pode contribuir com um contato mais frequente com o flúor. Já o estudo de Salcedo et al., em 2010, não encontrou relação entre a fluorose e o IMC em estudantes de 6 a 11 anos; porém este estudo foi realizado em Portugal, com uma sub amostra de somente 20 crianças. O Índice de fluorose comunitária acompanhou esta tendência, apresentando-se mais elevado nos adolescente com SPO $(0,28)$ quando comparado com EUT $(0,18)$. O valor para a amostra total $(0,22)$ apresentou-se sem importância sob o ponto de vista de saúde pública, não havendo necessidade de intervenções em relação à fluoretação da água de abastecimento público.

Alterações nas condições gengivais podem ser observadas em elevadas proporções em adolescentes (SCHROEDER \& RIBEIRO, 2004). Na presente pesquisa observou-se que uma prevalência de alterações periodontais maior em adolescentes EUT $(65,91 \%)$ em relação aos adolescentes com SPO $(52,31 \%)$, contrariando outros estudos na literatura, que observaram uma presença maior de alterações periodontais em adolescente com SPO (REEVES et al., 2006; MODÉER et al., 2011). Esta discrepância de resultados pode ter ocorrido pela idade dos adolescentes empregada neste estudo. Segundo Reeves et al., em 2006, 
adolescentes com idades inferiores a 17 anos não apresentam risco aumentado para periodontite crônica, enquanto adolescentes com idade acima de 17 anos tinham um risco aumentado para cada $1 \mathrm{~kg}$ de aumento de peso corporal. Além disso, observou-se maior presença de cálculo dentário em EUT (44,32\%) quando comparados com SPO $(29,23 \%)$, sugerindo uma diferença na qualidade e frequência na higienização bucal entre os dois grupos.

Muitos países têm procurado medidas de controle e tratamento da cárie dentária, doença até então considerada o grande problema de saúde pública na Odontologia. Com a expressiva redução de sua prevalência, outros agravos à saúde bucal têm despertado maior atenção da comunidade científica (PERES \& ARMÊNIO, 2006), como as lesões dentárias não cariosas (SALES-PERES et al., 2008). Neste estudo, todos os adolescentes avaliados apresentaram desgaste dentário em pelo menos um elemento dentário. Evidenciou-se associação entre a severidade do desgaste dentário e o IMC $(p<0,05)$, sendo que os adolescentes com SPO apresentaram uma chance maior de desgaste em dentina quando comparado aos adolescentes EUT. Este dado é reforçado pelo estudo de Tong et al., em 2013, que observaram maior risco de erosão dentária em crianças obesas.

A realização de estudos epidemiológicos visando o diagnóstico das oclusopatias pode ser valiosa para avaliação das necessidades e estabelecimento de prioridades para o seu tratamento, prevenção e também para obter informações para alocar recursos necessários para provisão de tratamento para população. Recentemente, o tratamento ortodôntico foi incluído no elenco de alternativas terapêuticas dos Centros de Especialidades Odontológicas do Sistema Único de Saúde (BORGES et al., 2010). Neste estudo, os adolescentes avaliados apresentaram alta prevalência de má oclusão (73,86\%), sendo observado sem anormalidades/oclusopatias leves em apenas $29,23 \%$ dos adolescentes com SPO, e 22,73\% dos adolescentes EUT; não sendo, porém observadas diferenças significativas entre os grupos. Os valores encontrados, independente dos grupos, podem ser considerados elevados quando em comparação com os dados obtidos pelo SB Brasil 2010, que encontrou uma prevalência de 40,90\% de má oclusão em adolescentes aos 12 anos no Brasil, conforme o demonstrado no estudo de interpretação dos dados deste levantamento conduzido em 2013 por Brizon et al.; e à Flores et al., também em 2013, que em seu estudo que correlacionou esta condição ao estado nutricional de escolares de 7 a 12 anos de idade, 33,0\% de má 
oclusão em EUT, e 29,3\% em SPO. Deve-se ressaltar que o uso de aparelhos ortodônticos foi um dos critérios de exclusão dos adolescentes nesta pesquisa, havendo, portanto, um amplo número de participantes da pesquisa que não tiveram acesso a este tipo de tratamento. Este dado se mostra de suma importância, pois as alterações no crescimento e desenvolvimento que afetam a oclusão dos dentes, definidas como má-oclusão, são consideradas problemas de saúde pública, sendo altamente prevalentes e podendo interferir nos aspectos psicossociais e nas relações sociais, ocasionando impacto negativo na qualidade de vida (MARQUES et al., 2005).

O fluxo salivar nos adolescentes estudados revelou uma média geral de $0,75 \mathrm{ml} / \mathrm{min}$, apresentando-se de forma bem semelhante em ambos os grupos (G1, 0,76; G2, 0,75). Os valores obtidos não demonstraram diferenças estatísticas entre os grupos e em relação ao IMC, estando de acordo com a pesquisa de Panunzio et al., em 2010. Porém; estes autores observaram que a composição da saliva apresentava-se com características diferentes nos adolescentes com SPO, com alterações nas concentrações salivares de fosfato, ácido siálico, proteínas e na atividade da peroxidase, as quais favorecem a formação de cárie dentária. Neste estudo, observou-se porém, que a maioria dos adolescentes apresentaram um quadro de hipossalivação, o que não é justificado pela idade, conforme pesquisou Moura et al., em 2008, que não encontraram diferenças de fluxo salivar decorrente da faixa etária. Estes mesmos autores, inclusive, observaram um valor de fluxo salivar na faixa etária de 6 a 12 anos $(0,73 \mathrm{ml} / \mathrm{min})$ muito semelhante ao encontrado neste estudo. A condição de hipossalivação demonstra-se ser preocupante, pois a saliva desempenha um importante papel na prevenção das principais enfermidades bucais, como a cárie dentária, a doença periodontal e o desgaste dentário. (FENOLL-PALOMARES et al., 2004). Por essa razão o conhecimento do fluxo salivar é importante para se compreender melhor os riscos da ocorrência de alterações bucais. Segundo Guaré et al., em 2013, é importante considerar a contribuição de parâmetros salivares na experiência de cárie dentária de crianças e adolescentes com excesso de peso, e também na implementação de medidas preventivas nesta população. 
6.3 QUALIDADE DE VIDA

A meta para 2020 da OMS é minimizar os impactos das doenças bucais e craniofaciais sobre a saúde geral e o bem estar psicossocial (HOBDELL et al, 2003). Deve-se dar ênfase deste conceito em adolescentes, pois este é um período da vida em que ocorrem grandes mudanças físicas e psicológicas, altamente influenciadas por fatores genéticos, étnicos e ainda pelas diferentes situações sociais e ambientais (SALES-PERES et al., 2010). A obesidade em crianças e adolescentes parece também estar envolvida em consequências psicológicas e sociais, pois pode comprometer a autoestima do jovem obeso (ABRANTES et al., 2002).

A mensuração da qualidade de vida se tornou um importante indicador de saúde, pois fornece informações a respeito da interferência da condição clínica na vida do paciente, podendo direcionar para políticas públicas que visem à melhoria da qualidade de vida. Neste estudo, utilizou-se o questionário CHILD-OIDP, adaptado para a língua portuguesa (CASTRO et al., 2008), para avaliação do impacto nas condições bucais e no desempenho diário de adolescentes. Na primeira etapa, independente do grupo avaliado, as condições bucais referidas com maior frequência pelos adolescentes foram dentes sensíveis, posição dentária e cor dos dentes (Tabela 15). A condição mais prevalente encontrada, dentes sensíveis, corrobora com outros estudos já realizados utilizando este mesmo questionário (TUBERT-JEANNIN et al., 2005; CASTRO et al., 2008; CASTRO et al., 2011). A posição dos dentes também foi percebida pelos adolescentes, possivelmente estando relacionada com a alta prevalência de oclusopatias observada neste estudo, assim como a questão estética, que ficou evidente pela também citação da cor dos dentes nesta primeira etapa.

Em relação ao escore total do questionário não observou-se diferenças entre os grupos $(p>0,05)$. Na segunda etapa do questionário, que analisou a relação entre a prevalência e a severidade do impacto das condições bucais nas atividades diárias, observou-se nos adolescentes com SPO impacto moderado em comer, estado emocional e sorrir. Nos adolescentes EUT, observou-se impacto moderado em sorrir e pequeno em comer e higienização bucal. Observa-se que o impacto no desempenho diário comer denota prejuízo no aspecto funcional, enquanto o estado emocional e sorrir, prejuízo no aspecto psicológico. Isto pode sugerir que os adolescentes com SPO, apesar de possuírem condição bucal semelhante aos EUT, 
possui uma maior percepção do impacto destas condições em sua qualidade de vida. Essa interpretação corrobora com os resultados encontrados por Chakravathy et al., em 2013, que em seu estudo observaram que os adolescentes com aumento do IMC relataram baixa qualidade de vida relacionada à saúde bucal; e ao estudo de Freitas et al., em 2014, sobre a associação entre obesidade infantil e o impacto bucal na qualidade de vida, em que os autores observaram a influência de aspectos psicológicos (sorrir e estado emocional) na qualidade de vida dos adolescentes com sobrepeso/obesidade.

Quando correlacionadas as condições bucais aos escores gerais do CHILD-OIDP observou-se associação negativa com o fluxo salivar em adolescentes do grupo SPO. Como a diminuição do fluxo salivar contribui para uma maior suscetibilidade a doenças bucais, pode-se sugerir que os adolescentes nesta condição apresentaram uma maior insatisfação com sua condição bucal, interferindo diretamente na sua qualidade de vida.

A aplicação do questionário demonstrou-se ser uma das possíveis limitações deste estudo, podendo-se atribuir à auto percepção dos adolescentes em entender e responder ao questionário, uma vez que os problemas bucais podem ser superestimados por estes indivíduos, entretanto este ponto foi levado em consideração pelos autores na elaboração deste questionário (GHERUNPONG et al., 2004). 


\section{Conclusões}



7 CONCLUSÕES

A partir do exposto pode-se concluir que:

$\checkmark$ É fundamental uma abordagem estratégica e multidisciplinar da obesidade e dos fatores de risco que predispõem para esta doença, uma vez que estes podem resultar em agravos à saúde bucal dos adolescentes;

$\checkmark$ Dentre os adolescentes avaliados 40,52\% apresentavam-se com sobrepeso ou obesidade, sendo este valor superior ao observado no Brasil em 2010;

$\checkmark$ Os adolescentes com sobrepeso/obesidade apresentaram-se com uma menor prevalência de cárie dentária e de alterações periodontais em relação aos eutróficos, porém sem diferenças significativas;

$\checkmark$ Os adolescentes com sobrepeso/obesidade apresentaram maior prevalência de fluorose dentária e maior índice de fluorose comunitária do que os eutróficos, sem apresentar, porém diferenças significativas;

$\checkmark$ A prevalência do desgaste dentário foi semelhante entre os grupos, porém houve diferença significativa em relação à severidade do desgaste dentário nos adolescentes com sobrepeso/obesidade;

$\checkmark$ Os adolescentes apresentaram alta prevalência de má oclusão dentária e fluxo salivar reduzido, entretanto não foram observadas diferenças significantes entre os grupos;

$\checkmark$ A percepção dos adolescentes em relação aos impactos odontológicos no desempenho de suas atividades diárias apresentou-se baixa, sendo que os adolescentes com sobrepeso/obesidade relataram prejuízo nos domínios relacionados aos aspectos psicológicos, enquanto os eutróficos nos relacionados aos aspectos funcionais;

$\checkmark$ Não foram observadas associações entre qualidade de vida, cárie dentária e má-oclusão, porém observou-se correlação negativa entre o fluxo salivar e a qualidade de vida nos adolescentes com sobrepeso/obesidade. 

Referências 



\section{REFERÊNCIAS}

Abrantes MM, Lamounier JA, Colsimo EA. Prevalência de sobrepeso e obesidade nas regiões sudeste e nordeste. J Pediatr. 2002;78:335-40.

Adulyanon S, Vourapukjaru J, Sheiham A. Oral impacts affecting daily performance in a low dental disease Thai population. Community Dent Oral Epidemiol 1996;24(6):385-9.

Alves LS, Susin C, Damé-Teixeira N, Maltz M. Overweight and obesity are not associated with dental caries among 12-year-old South Brazilian schoolchildren. Community Dent Oral Epidemiol. 2013;41(3):224-31.

Anjos L. Antropometria nutricional: uso de dados de peso e de altura na avaliação do estado nutricional de crianças com menos de 10 anos de idade. Revista Ciência e Movimento. 1988; 2(1):7-16.

Antunes JLF, Peres MA, Frazão P. Cárie dentária. In: Antunes JLF, Peres MA. Epidemiologia da saúde bucal. $1^{\mathrm{a}} \mathrm{ed}$. Rio de Janeiro: Guanabara Koogan; 2006. Cap 1. p.49-67.

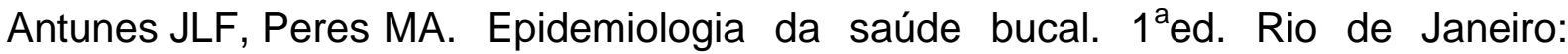
Guanabara Koogan; 2006.

Barbosa TS, Mialhe FL, Castilho ARF, Gavião MDB. Qualidade de vida e saúde bucal em crianças e adolescentes: aspectos conceituais e metodológicos. Physis Revista de Saúde Coletiva. 2010;20(1):283-300.

Barron RP, Carmichael RP, Marcon MA, Sàndor GKB. Dental erosion in gastroesophageal reflux disease. J Can Dent Assoc. 2003;69(2):84-9.

Bastos RS. Declínio de cárie dentária e incremento no percentual de escolares de 12 anos de idade, livres da doença, em Bauru, São Paulo, entre 1976 e 2001. [dissertação]. Bauru (SP): Faculdade de Odontologia de Bauru. Universidade de São Paulo; 2001.

Borges CM, Peres MA, Peres KG. Association between malocclusion and dissatisfaction with dental and gingival appearance: study with Brazilian adolescents. Rev Bras Epidemiol. 2010;13(4):713-23. 
Brasil, Lei Federal $n^{0} 6.050$, de 24 de maio de 1974. Dispõe sobre a fluoretação de água em sistemas de abastecimento quando existir estação de tratamento. Diário Oficial da União. Brasília-DF, 1976.

Brasil. Ministério da Saúde. Secretaria de Atenção à Saúde. Departamento de Atenção Básica. Projeto SB Brasil 2010: pesquisa nacional de saúde bucal: resultados principais. Brasília-DF, 2011.

Brasil. Ministério do Planejamento, Orçamento e Gestão. Instituto Brasileiro de Geografia e Estatística (IBGE). Pesquisa de Orçamento Familiar (POF) 2008/2009. Antropometria e estado nutricional de crianças, adolescentes e adultos no Brasil. Brasília-DF, 2010.

Brasil. Ministério do Planejamento, Orçamento e Gestão. Instituto Brasileiro de Geografia e Estatística (IBGE). Censo demográfico 2010. Disponível em: http://cidades.ibge.gov.br/xtras/perfil.php?lang=\&codmun=350600. Acesso em: 01/02/2014.

Brizon VSC, Cortellazzi KL, Vazquez FL, Ambrosano GMB, Pereira AC, Gomes VE, et al. Fatores individuais e contextuais associados à má oclusão em crianças brasileiras. Rev Saúde Pública 2013;47(Supl 3):118-28.

Buchwald H, Williams SE. Bariatric surgery worldwide 2003. Obes Surg. 2004;14(9):1157-64.

Campos DL, Farias DG, Toledo OA, Bezerra ACB. Prevalence of dental fluorosis in school children from Brasília - Federal District. Revista de Odontologia da Universidade de São Paulo. 1998;12(3):225-30.

Castro RAL, Cortes MIS, Leão AT, Portela MC, Souza IPR, Tsakos G, et al. ChildOIDP index in Brazil: cross-cultural adaptation and validation. Health Qual Life Outcomes. 2008;6:68.

Castro RAL, Portela MC, Leão AT, Vasconcellos MTL. Oral health-related quality of life of 11- and 12-year-old public school children in Rio de Janeiro. Community Dent Oral Epidemiol. 2011;39(4):336-44.

Cattaneo A, Monasta L, Stamatakis E, Lioret S, Castetbon K, Frenken F, et al. Overweight and obesity in infants and pre-school children in the European Union: a review of existing data. Obes Rev. 2010;11(5):389-98. 
Chakravathy KP, Thippeswamy HM, Kumar N, Chenna D. Relationship of body mass index and dental caries with oral health related quality of life among adolescents of Udupi district, South India. Eur Arch Paediatr Dent. 2013;14(3):155-9.

Cinar $\mathrm{AB}$, Murtomaa $\mathrm{H}$. Interrelation between obesity, oral health and life-style factors among Turkish school children. Clin Oral Investig. 2011;15(2):177-84.

Crispim MGA, Grillo LP, Próspero ENS, Mariath AB. Saúde bucal e sua associação com o estado nutricional e a condição socioeconômica em adolescentes. RGO Revista Gaúcha de Odontologia. 2010;58(1):41-6.

Dean HT. Classification of mottled enamel diagnosis. J Am Dent Assoc 1934 21:1421-6.

Dietz WH, Robinson TN. Use of the body mass index (BMI) as a measure of overweight in children and adolescents. J Pediatr. 1998;132(2):191-3.

Douek PC, Leone C. Nutritional status of young children: a comparison among three anthropometric classifications. J Pediatr (Rio J). 1995;71(3):139-44.

Fadel HT, Pliaki A, Gronowitz E, Mårild S, Ramberg P, Dahlèn G, et al. Clinical and biological indicators of dental caries and periodontal disease in adolescents with or without obesity. Clin Oral Investig. 2013 Mar 21;

Fenoll-Palomares C, Muñoz Montagud JV, Sanchiz V, Herreros B, Hernández V, Mínguez $\mathrm{M}$, et al. Unstimulated salivary flow rate, $\mathrm{pH}$ and buffer capacity of saliva in healthy volunteers. Rev Esp Enferm Dig. 2004;96(11):773-83.

Flores XDS, Benavides RCR, Barrera JC, Rodríguez JDL. Prevalence of caries, gingivitis and malocclusions in school-age children in Ciudad Victoria, Tamaulipas, and its relationship with their nutritional status. Revista Odontológica Mexicana. 2013;17(4):217-23.

Franchini R, Petri A, Migliario M, Rimondini L. Poor oral hygiene and gingivitis are associated with obesity and overweight status in paediatric subjects. J Clin Periodontol. 2011;38(11):1021-8.

Francischi RPP, Pereira LO, Freitas CS, Klopfer M, Santos RC, Vieira P, et al. Obesidade: atualização sobre etiologia, morbidade e tratamento. Rev Nutr. 2000;13(1):17-28. 
Freire MCM, Reis SCGB, Figueiredo N, Peres KG, Moreira RS, Antunes JLF. Determinantes individuais e contextuais da cárie em crianças brasileiras de 12 anos em 2010. Rev Saúde Pública 2013;47(Supl 3):40-9.

Freitas AR, Aznar FD, Tinós AM, Yamashita JM, Sales-Peres A, Sales-Peres SH. Association between dental caries activity, quality of life and obesity in Brazilian adolescents. Int Dent J. 2014;64(6):318-23.

Freitas CHSM, Sampaio FC, Roncalli AG, Moysés SJ. Reflexões metodológicas sobre prevalência da fluorose dentária nos inquéritos de saúde bucal. Rev Saúde Pública 2013;47(Supl 3):138-47.

Frisbee SJ, Chambers CB, Frisbee JC, Goodwill AG, Crout RJ. Self-reported dental hygiene, obesity, and systemic inflammation in a pediatric rural community cohort. BMC Oral Health. 2010;10:21.

Garrido Junior AB, Ferraz EM, Barroso FL, Marchesini JB, Szego T. $2^{a}$ ed. Cirurgia da obesidade. São Paulo: Atheneu; 2006.

Gherunpong S, Tsakos G, Sheiham A. Developing and evaluating an oral healthrelated quality of life index for children; the CHILD-OIDP. Community Dent Health. 2004;21(2):161-9.

Goodson JM, Tavares M, Wang X, Niederman R, Cugini M, Hasturk H, et al. Obesity and dental decay: inference on the role of dietary sugar. PLoS One. 2013;8(10):e74461.

Greenway SE, Greenway FL. Root surface caries: a complication of the jejunoileal bypass. Obes Surg. 2000;10(1):33-6.

Guaré RO, Ciamponi AL, Santos MTBR, Gorjão R, Diniz MB. Caries Experience and Salivary Parameters among Overweight Children and Adolescents. Dent $\mathrm{J}$. 2013;1:31-40.

Guo SS, Chumlea WC. Tracking of body mass index in children in relation to overweight in adulthood. Am J Clin Nutr. 1999;70(1):145S-8S.

Heling I, Sgan-Cohen HD, Itzhaki M, Beglaibter N, Avrutis O, Gimmon Z. Dental complications following gastric restrictive bariatric surgery. Obes Surg. 2006;16(9):1131-4. 
Hobdell M, Petersen PE, Clarkson J, Johnson N. Global goals for oral health 2020. Int Dent J. 2003;53(5):285-8.

Irigoyen-Camacho ME, Sanchez-Perez L, Molina-Frechero N, Velazquez-Alva C, Zepeda-Zepeda M, Borges-Yanez A. The relationship between body mass index and body fat percentage and periodontal status in Mexican adolescents. Acta Odontol Scand. 2014;72(1):48-57.

Jokovic A, Locker D, Stephens M, Kenny D, Tompson B, Guyatt G. Validity and reliability of a questionnaire for measuring child oral-health-related quality of life. J Dent Res. 2002;81(7):459-63.

Jones $\mathrm{CM}$, Worthington $\mathrm{H}$. Water fluoridation, poverty and tooth decay in 12-year-old children. J Dent. 2000;28(6):389-93.

Kelishadi R, Mortazavi S, Hossein TR, Poursafa P. Association of cardiometabolic risk factors and dental caries in a population-based sample of youths. Diabetol Metab Syndr. 2010;2:22.

Kiess W, Reich A, Müller G, Galler A, Kapellen T, Raile K, et al. Obesity in childhood and adolescence: clinical diagnosis and management. J Pediatr Endocrinol Metab. 2001;14 Suppl 6:1431-40.

Laitinen J, Power C, Järvelin MR. Family social class, maternal body mass index, childhood body mass index, and age at menarche as predictors of adult obesity. Am J Clin Nutr. 2001;74(3):287-94.

Landis JR, Koch GG. The measurement of observer agreement for categorical data. Biometrics. 1977;33(1):159-74.

Leão AT, Locker D. Impacto das condições de saúde bucal na qualidade de vida. In: Antunes JLF, Peres MA. Epidemiologia da saúde bucal. $1^{a}$ ed. Rio de Janeiro: Guanabara Koogan; 2006. Cap 3. p.260-8.

Leão ATT, Cidade MC, Varela JR. Impactos da saúde periodontal na vida diária. Rev Bras Odontol. 1998;55(4):238-41.

Lima LP, Sampaio HAC. Socioeconomic, anthropometric and food intake characterization of severely obese people. Cien Saude Colet. 2007;12(4):1011-20. 
Marcenes W, Steele JG, Sheiham A, Walls AWG. The relationship between dental status, food selection, nutrient intake, nutritional status, and body mass index in older people. Cad Saude Publica. 2003;19(3):809-16.

Marcenes W, Bonecker MJS. Aspectos epidemiológicos e sociais das doenças bucais. In: Lascala NT. Promoção de saúde bucal na clínica odontológica. São Paulo: Artes Médicas; 2000.

Marques LS, Barbosa CC, Ramos-Jorge ML, Pordeus IA, Paiva SM. Malocclusion prevalence and orthodontic treatment need in 10-14-year-old schoolchildren in Belo Horizonte, Minas Gerais State, Brazil: a psychosocial focus. Cad Saude Publica. 2005;21(4):1099-106.

Marshall TA, Eichenberger-Gilmore JM, Broffitt BA, Warren JJ, Levy SM. Dental caries and childhood obesity: roles of diet and socioeconomic status. Community Dent Oral Epidemiol. 2007;35(6):449-58.

Mathus-Vliegen EMH, Nikkel D, Brand HS. Oral aspects of obesity. Int Dent J. 2007;57(4):249-56.

Mertens IL, Van Gaal LF. Promising new approaches to the management of obesity. Drugs. 2000;60(1):1-9.

Modéer T, Blomberg C, Wondimu B, Lindberg TY, Marcus C. Association between obesity and periodontal risk indicators in adolescents. Int J Pediatr Obes. 2011;6(22):e264-270.

Modéer T, Blomberg CC, Wondimu B, Julihn A, Marcus C. Association between obesity, flow rate of whole saliva, and dental caries in adolescents. Obesity. 2010;18(12):2367-73.

Moreira PVL. Estudo comparativo da prevalência de cárie em adolescentes eutróficos e obesos de 12 a 15 anos de idade em escolas públicas e privadas na cidade de João Pessoa - PB. [tese]. Camaragibe (PE): Faculdade de Odontologia, Universidade de Pernambuco; 2003.

Moura JKD, Barros LA, Oliveira AEF, Ribeiro CCC, Lopes FF. Avaliação quantitativa do fluxo salivar estimulado em crianças e adolescentes. Rev odonto ciênc. 2008;23(4):380-3. 
Moynihan P, Lingstrom P, Rugg-Gunn, AJ, Birkhed D. O papel do controle da dieta. In: Ferjeskov, O.; Kidd, E. Cárie dentária - A doença e seu tratamento clínico. $1^{\mathrm{a} e d}$. São Paulo: Santos Editora; 2005. Cap 12. p.223-42.

Navarro MFL, Cortes DF. Avaliação e tratamento do paciente com relação ao risco de cárie. Maxi-Odonto: dentistica. 1995;1(4):1-16.

Oliveira-Junior SR, Cangussu MCT, Lopes LS, Soares AP, Ribeiro AA, Fonseca LA. Dental fluorosis in schoolchildren 12 and 15 years of age in Salvador, Bahia, Brazil, in 2001 and 2004. Cad Saude Publica. 2006;22(6):1201-6.

Pannunzio E, Amancio OMS, Vitalle MSS, Souza DN de, Mendes FM, Nicolau J. Analysis of the stimulated whole saliva in overweight and obese school children. Rev Assoc Med Bras. 2010;56(1):32-6.

Peres KG, Armênio MF. Erosão dental. In: Antunes JLF, Peres MA. Fundamentos de Odontologia: epidemiologia bucal. $1^{\mathrm{a} e d}$. Rio de Janeiro: Guanabara Koogan; 2006. Cap 15. p.195-204.

Peres KG, Bastos JR, Latorre MR. Severity of dental caries in children and relationship with social and behavioral aspects. Rev Saude Publica. 2000;34(4):4028.

Piovesan C, Batista A, Ferreira FV, Ardenghi TM. Oral health-related quality of life in children: Conceptual issues. Rev Odont Cienc. 2009;24(1):81-5.

Reeves AF, Rees JM, Schiff M, Hujoel P. Total body weight and waist circumference associated with chronic periodontitis among adolescents in the United States. Arch Pediatr Adolesc Med. 2006;160(9):894-9.

Ribeiro Junior HC. A pandemia de obesidade entre jovens. Revista Paulista de Pediatria. 2007;25(4):304.

Salcedo ISM, Castro LVS, Marino R, Campelo A. Fluorosis, diet and nutritional status in schoolchildren from Northern Portugal. In: The Preliminary Program for IADR General Session; 2010 julho 14-17; Barcelona, Espanha.

Sales-Peres SHC, Goya S, Sant'Anna RMF, Silva HM, Sales-Peres AC, Silva RPR, et al. Prevalence of overweight and obesity, and associated factors in adolescents, at the central west area of the state São Paulo (SP, Brazil). Cien Saude Colet. 2010;15 Suppl 2:3175-84. 
Sales-Peres SHC, Goya S, Araújo JJ, Sales-Peres A, Lauris JRP, Buzalaf MAR. Prevalence of dental wear among 12-year-old Brazilian adolescents using a modification of the tooth wear index. Public Health. 2008;122(9):942-8.

Saliba NA, Moimaz SAS, Saliba O, Santos KT, Sundfeld RH, Lelis RT. Fluorose dentária em jovens não expostos à água fluoretada durante a formação dentária. Arq Odontol 2006;42(2):113-23.

Santo MA, Cecconello I. Morbid obesity: risks control. Arq Gastroenterol. 2008;45(1):1-2.

Schroeder MDS, Ribeiro GLU. Avaliação do índice gengival e de placa com apinhamento dentário no desenvolvimento de gengivites em crianças e adolescentes. RSBO. 2004;1(1):17-21.

Shailee F, Sogi GM, Sharma KR. Association between Dental caries and body mass index among 12 and 15 years school children in Shimla, Himachal Pradesh. J. Adv Oral Research. 2012;4(1):7-14.

Sinha R, Fisch G, Teague B, Tamborlane WV, Banyas B, Allen K, et al. Prevalence of impaired glucose tolerance among children and adolescents with marked obesity. N Engl J Med. 2002;346(11):802-10.

Slade GD. Assessing change in quality of life using the Oral Health Impact Profile. Community Dent Oral Epidemiol. 1998;26(1):52-61.

Tambelini CA, Ramos DM, Poli-Frederico RC, Tomasetti CSC, Barata TJE, Maciel SM. Dental caries in adolescents and its association with excess weight and sociodemographic factors in Londrina, Paraná, Brazil. Revista Odonto Ciência. 2010;25(3):245-9.

Taubes G. As obesity rates rise, experts struggle to explain why. Science. 1998;280(5368):1367-8.

Terada RSS, Hayacibara MF, Marchi V, Ramos MJ. Fluorose dental em adolescentes da rede estadual de ensino de Maringá - PR. Cad Saúde Colet. 2009;17(2):351-60.

Tesch FC, Oliveira BH, Leão A. Measuring the impact of oral health problems on children's quality of life: conceptual and methodological issues. Cad Saude Publica. 2007;23(11):2555-64. 
Tong HJ, Rudolf MCJ, Muyombwe T, Duggal MS, Balmer R. An investigation into the dental health of children with obesity: an analysis of dental erosion and caries status. Eur Arch Paediatr Dent. 2013;15(3):203-10.

Touger-Decker R, Mobley CC, American Dietetic Association. Position of the American Dietetic Association: oral health and nutrition. J Am Diet Assoc. 2007;107(8):1418-28.

Traebert J, Moreira EAM, Bosco VL, Almeida ICS. Transição alimentar: problema comum à obesidade e à cárie dentária. Rev Nutr 2004;17(2):247-53.

Traebert JL, Peres MA, Galesso ER, Zabot NE, Marcenes W. Prevalence and severity of dental caries among schoolchildren aged six and twelve. Rev Saude Publica. 2001;35(3):283-8.

Tripathi S, Kiran K, Kamala B K. Relationship between obesity and dental caries in children - A preliminary study. J. Int Oral Health. 2010;2(4):65-72.

Tubert-Jeannin S, Pegon-Machat E, Gremeau-Richard C, Lecuyer M, Tsakos G: Validation of a French version of Child-OIDP index. Eur J Oral Sci. 2005;113:355362.

Vasconcelos VL, Silva GAP. Overweight and obesity prevalences in male adolescents in Northeast Brazil, 1980-2000. Cad Saude Publica. 2003;19(5):144551.

WHO. World Health Organization. Growth reference data for 5-19 years. 2007. Disponível em: http://www.who.int/growthref. Acesso em: 01/06/2015.

WHO. World Health Organization. Health topics. Obesity. 2015. Disponível em: http://www.who.int/topics/obesity/en/. Acesso em: 01/06/2015.

WHO. World Health Organization. Oral health surveys: basic methods. $4^{\mathrm{a}}$ ed. Geneva: ORH/EPID; 1997.

Zeigler CC, Persson GR, Wondimu B, Marcus C, Sobko T, Modéer T. Microbiota in the oral subgingival biofilm is associated with obesity in adolescence. Obesity. 2012;20(1):157-64. 

Anexos 



\section{ANEXO A - Carta de aprovação do CEP}

\section{FACULDADE DE ODONTOLOGIA DE BAURU-}

\section{PROJETO DE PESQUISA}

Título: Análise das condições bucais, do estado nutricional e da qualidade de vida de adolescentes residentes no município de Bauru-SP

\section{Área Temática:}

Área 9. A critério do CEP.

Versão: 2

CAAE: $\quad 06395012.8 .0000 .5417$

Pesquisador: Silvia Helena de Carvalho Sales Peres

Instituição: Faculdade de Odontologia de Bauru-USP

\section{PARECER CONSUBSTANCIADO DO CEP}

$\begin{array}{lc}\text { Número do Parecer: } & 111.649 \\ \text { Data da Relatoria: } & 26 / 09 / 2012\end{array}$

Apresentação do Projeto:

Parecer anterior

Objetivo da Pesquisa:

Parecer anterior

Avaliação dos Riscos e Benefícios:

Parecer anterior

Comentários e Considerações sobre a Pesquisa:

Parecer anterior

\section{Considerações sobre os Termos de apresentação obrigatória:}

Os autores esclareceram que participarão como examinadores apenas os dois pesquisadores Adriana Rodrigues de Freitas e Fábio Duarte da Costa Aznar, que constam no Termo de Aquiescência da Secretaria da Educação que foi encaminhado inicialmente. O cronograma foi atualizado.

\section{Recomendações:}

Não há.

Conclusões ou Pendências e Lista de Inadequações:

Considerando que a documentação está de acordo com a Resolução 196/96, sou de parecer favorável a aprovação deste projeto.

Situação do Parecer:

Aprovado

Endereç: DOUTOR OCTAVIO PINHEIRO BRISOLLA 75 QUADRA 9

Bairro: VILA NOVA CIDADE UNIVERSITARIA CEP: $17.012-90$

UF: SP Município: BAURU

Telefone: (14)3235-8356 Fax: (14)3235-8356 E-mail: mferrari@fob.usp.br 


\section{FACULDADE DE ODONTOLOGIA DE BAURU-}

Necessita Apreciação da CONEP:

Não

Considerações Finais a critério do CEP:

O CEP acata o parecer do relator.

Esse projeto foi considerado APROVADO. O CEP-FOB/USP exige a apresentação de relatórios anuais (parciais e finais), conforme o cronograma apresentado. Qualquer alteração na metodologia e/ou título e a inclusão ou exclusão de autores deverá ser prontamente comunicada. Lembramos que na apresentação do relatório final, deverão ser incluídos todos os TCLEs e/ou termos de doação de dentes devidamente assinados e rubricados.

BAURU, 01 de Outubro de 2012

Assinado por:

Maria Teresa Atta

(Coordenador)

Endereço: DOUTOR OCTAVIO PINHEIRO BRISOLLA 75 QUADRA 9

Bairro: VILA NOVA CIDADE UNIVERSITARIA CEP: $17.012-901$

UF: SP Municipio: BAURU

Telefone: (14)3235-8356 Fax: (14)3235-8356 E-mail: mferrari@fob.usp.br 
ANEXO B - Autorização da Secretaria Municipal de Educação de Bauru - SP para a realização deste estudo

\section{PREFEITURA DO MUNICÍPIO DE BAURU \\ Estado de São Paulo \\ SECRETARIA DA EDUCAÇÃO \\ Fone - (014) 3234-1977 \\ End: Rua Padre João nº 8-48 - Vila Régis \\ CEP- 17014-003}

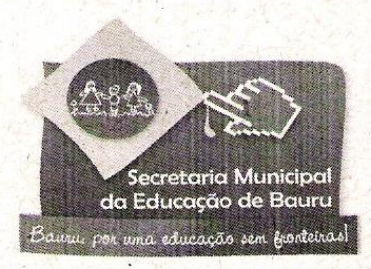

Bauru, 07 de agosto de 2012.

\section{DECLARAÇÃO DE AUTORIZAÇÃO .}

A Secretaria Municipal da Educação, por meio do Departamento de Planejamento, Projetos e Pesquisas Educacionais, Seção de Pesquisas Educacionais, autoriza os alunos ADRIANA RODRIGUES DE FREITAS e FÁBIO DUARTE DA COSTA AZNAR, da Faculdade de Odontologia de Bauru - USP, a realizar exame bucal nos adolescentes da rede municipal de ensino, na faixa etária de 12 anos, visando a obtenção de dados para o projeto de pesquisa "Análise das condições bucais, do estado nutricional e da qualidade de vida de adolescentes residentes

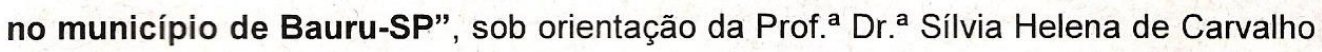
Sales Peres.

Salientamos que a equipe da Unidade Escolar tem autonomia para analisar e autorizar o desenvolvimento do projeto, de acordo com a disponibilidade da escola.

Atenciosamente.

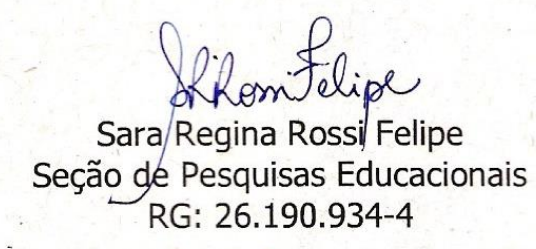


ANEXO C - Carta de informação entregue aos diretores das instituições.

\section{Carta de Consentimento - Escola}

$\mathrm{A} / \mathrm{C}$

Sr.(a) Diretor(a)

Estamos realizando um estudo intitulado "Análise das condições bucais, do estado nutricional e da qualidade de vida de adolescentes residentes no município de Bauru-SP". Para tanto, pedimos a sua colaboração no sentido de autorizar que realizemos os exames odontológico, antropométrico e questionário sobre qualidade de vida nos escolares.

Em caso afirmativo, será entregue à escola um consentimento pósinformado ao professor responsável para este pedir a vinda dos responsáveis das crianças para a assinatura do Termo de Consentimento Livre e Esclarecido. Em dia e horário marcado a combinar, iremos até sua escola para iniciar a coleta dos dados. É importante ressaltar que o contato será feito com outras instituições, com a finalidade de obter uma diversidade da amostra resultando numa pesquisa mais abrangente.

Contando com sua valiosa colaboração, colocamo-nos a vossa inteira disposição para os esclarecimentos que se fizerem necessários.

Atenciosamente,

Silvia Helena de Carvalho Sales Peres

Pesquisadora 
ANEXO D - Termo de consentimento livre e esclarecido (TCLE)

\section{TERMO DE CONSENTIMENTO LIVRE E ESCLARECIDO}

Pedimos aos senhores autorização para a participação de seus filhos nesta pesquisa que acontecerá na escola que ele estuda, onde eles serão atendidos.

Esta pesquisa tem como objetivos avaliar as condições de saúde bucal, estado nutricional e aspectos de qualidade de vida de escolares do municipio de Bauru - SP. Será realizado um exame da boca utilizando-se um espelho clinico para verificar a presença de cárie, problemas de gengiva, desgaste dos dentes, má oclusão (problemas na mastigação) e manchas causadas por excesso de flúor. $O$ adolescente também será avaliado quanto ao estado nutricional, sendo realizada sua medida por meio de fita métrica e balança, e responderá a um questionário sobre qualidade de vida. Este questionário é simples e leva em torno de cinco minutos para ser respondido. Esta pesquisa não oferece riscos aos seus participantes, porém alguns adolescentes podem sentir algum desconforto, e oferece como benefícios a distribuiçăo de kits de higiene bucal contendo escova, creme dental e material educativo sobre promoção de saúde bucal, e palestras informativas de educação em saúde. A participação de seu filho é voluntária. Assim como se houver vontade em retirar o seu filho do estudo em qualquer momento, não haverá nenhum problema. Os dados individuais dos seus filhos serão mantidos em sigilo, sendo manipulados somente pela responsável da pesquisa, assegurando proteção de sua imagem e respeitando valores morais, culturais, religiosos, éticos e sociais. Os resultados obtidos serão analisados e posteriormente divulgados para todos os interessados, a população em geral e em eventos cientificos, mas sua identidade năo será divulgada nestas apresentaçōes, nem serăo utilizadas quaisquer informaçōes que permitam sua identificaçăo. A pesquisadora estará a sua disposição para qualquer esclarecimento que considere necessário em qualquer etapa da pesquisa. Este estudo foi aprovado pelo Comitê de Ética em pesquisa da Faculdade de Odontologia de Bauru da Universidade de Sảo Paulo (FOB/USP). Quaisquer dúvidas poderăo ser esclarecidas pela Profa. Dra. Silvia Helena de Carvalho Sales-Peres (14-32358260).

Pedimos sua autorização e contamos com a sua participação.

Pelo presente instrumento que atende às exigèncias legais, $\circ$ (a) Sr. (a)

portador da cédula de identidade responsável

por após leitura minuciosa das informações constantes neste TERMO DE CONSENTIMENTO LIVRE E ESCLARECIDO devidamente explicada pelos profissionais em seus minimos detalhes, ciente dos serviços e procedimentos aos quais será submetido, năo restando quaisquer dúvidas a respeito do lido e explicado, firma seu CONSENTIMENTo LIVRE E ESCLARECIDO concordando em participar da pesquisa proposta.

Fica claro que o sujeito da pesquisa ou seu representante legal, pode a qualquer momento retirar seu CONSENTIMENTO LIVRE E ESCLARECIDO e deixar de participar desta pesquisa e ciente de que todas as informaçōes prestadas tornaram-se confidenciais e guardadas por força de sigilo profissional (Art. $9^{\circ}$ do Código de Ética Odontológica), e, caso queira apresentar reclamações em relação a sua participação na pesquisa, poderá entrar em contato com o Comitê de Ética em Pesquisa em Seres Humanos da FOB-USP pelo endereço Al. Dr. Octavio Pinheiro Brisolla, 9-75 (sala no prédio da Biblioteca, FOB-USP) ou pelo telefone (14) 3235-8356 ou (14) 3235-8357.

Por estarem de acordo assinam o presente termo.

Bauru - SP, de de 
Escola: Data:

Examinadores: Re-teste:

Índice ceod/CPOD - Cárie dentária e necessidade de tratamento

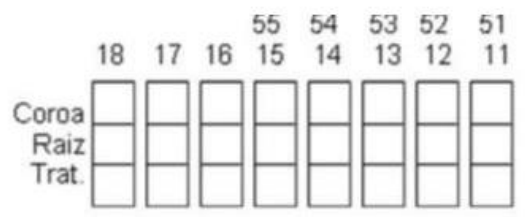

$\begin{array}{lllll}61 & 62 & 63 & 64 & 65\end{array}$

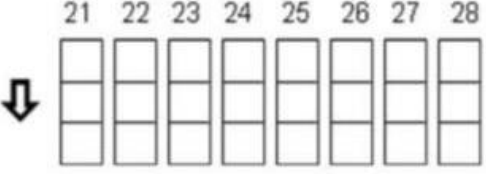

$\begin{array}{lllll}85 & 84 & 83 & 82 & 81\end{array}$

$\begin{array}{llllllll}48 & 47 & 46 & 45 & 44 & 43 & 42 & 41\end{array}$

$\begin{array}{lllll}71 & 72 & 73 & 74 & 75\end{array}$

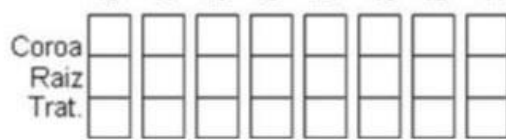

$\begin{array}{llllllll}31 & 32 & 33 & 34 & 35 & 36 & 37 & 38\end{array}$
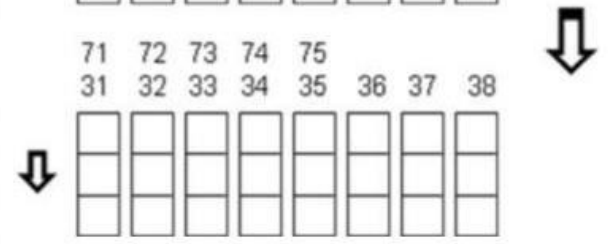

Índice de Desgaste Dentário (IDD)
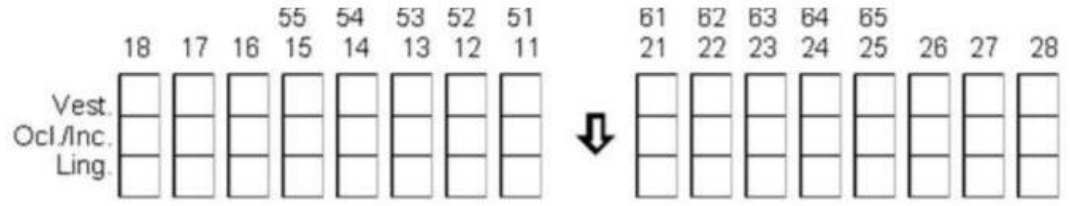

$\begin{array}{lllll}85 & 84 & 83 & 82 & 81\end{array}$
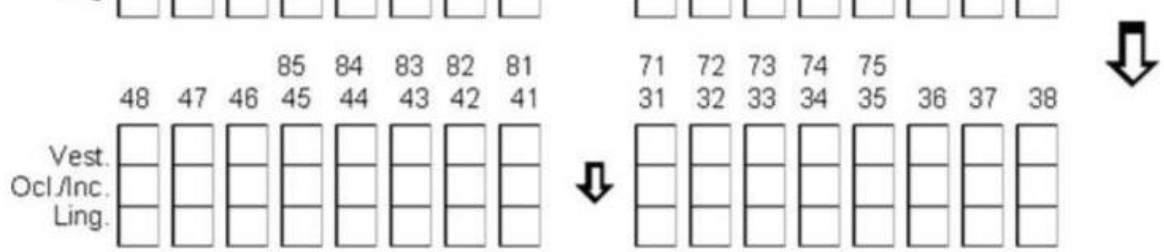

Índice Periodontal Comunitário, Fluorose Dentária e IMC

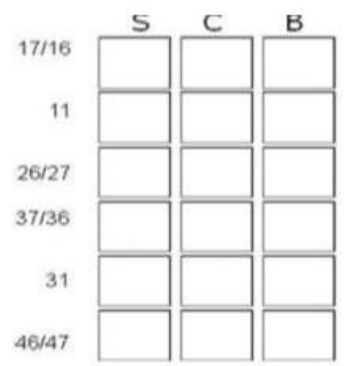

Fluorose Dentaria
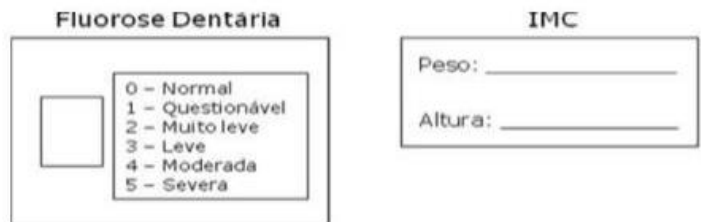

$\vec{\gamma}$

Sangramento: (0) Auséncia/(1) Presença Cálculo: (0) Ausência / (2) Presença Bolsa: (3) 4 a $5,5 \mathrm{~mm} /(4) 6 \mathrm{~mm}$ ou $+/(x)$ nulo 


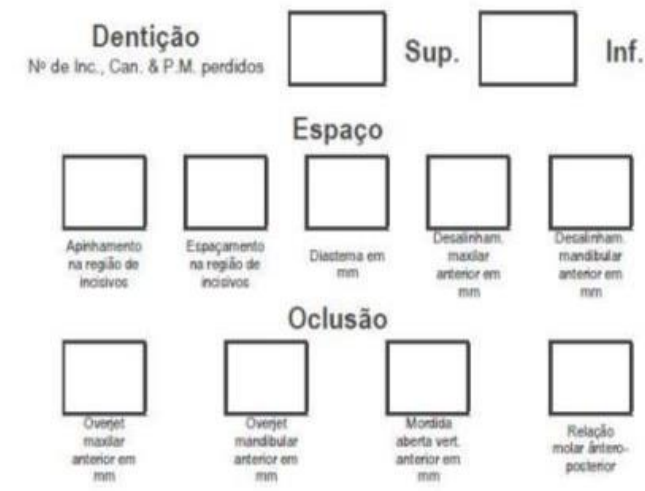

Teste de Fluxo Salivar

Fluxo Salivar $=$ $\mathrm{ml}=$ $\mathrm{ml} / \mathrm{min}$ 
ANEXO F - Questionário CHILD-OIDP

\section{Índice de Impactos Odontológicos no Desempenho das Atividades Diárias da Criança (Folha 1)}

Escola: Turma: Idade:

Nome:

Data de nascimento: I

Gênero: ( ) masculino ( ) feminino

$1^{a}$ Etapa: Nos últimos três meses, desde , você teve algum problema na sua boca ou nos seus dentes?

Marque com um $X$ o(s) problema(s) que você tem ou teve nos ültimos 3 meses.

$\square$ Dor de dente

$\square$ Dentes sensiveis (quando come ou bebe: doces, alimentos quentes como leite ou café e gelados como sorvete)

$\square$ Cárie ou buraco no dente

$\square$ Dente de leite mole

$\square$ Espaço entre os dentes (porque um dente permanente, novo ou definitivo, กão nasceu)

$\square$ Dente permanente (novo ou definitivo) quebrado

$\square$ Cor do dente (ex. mais amarelado, escuro ou manchado)

$\square$ Forma ou tamanho do dente (ex. dente com forma ou tamanho anormal, maior ou menor que os outros)

$\square$ Posição do dente (ex. dentes encavalados, trepados, tortos, para fora ou separados)

$\square$ Sangramento na gengiva (ex. quando escova os dentes)

$\square$ Gengiva inchada (ex. inflamada, ou mais avermelhada)

$\square$ Tártaro

$\square$ Feridas na boca

$\square$ Mau hálito (bafo)

$\square$ Boca ou rosto deformados (ex. lábio leporino, fenda palatina)

$\square$ Dente permanente (novo ou definitivo) nascendo

$\square$ Dente permanente (novo ou definitivo) perdido, faltando ou arrancado

Outros Quais? 
Formulário de Registro OIDP-Infantil (Folha 2)

\begin{tabular}{|c|c|c|c|c|}
\hline \multirow{2}{*}{ Atividades } & \multirow{2}{*}{ a) Gravidade } & \multicolumn{2}{|c|}{ b) Frequência } & \multirow{2}{*}{ c) Problemas } \\
\hline & & b1 & b2 & \\
\hline \multicolumn{5}{|l|}{$\begin{array}{c}\text { Comer (ex. refeição, } \\
\text { sorvete) }\end{array}$} \\
\hline \multicolumn{5}{|l|}{ Falar claramente } \\
\hline \multicolumn{5}{|l|}{$\begin{array}{l}\text { Limpar a boca (ex. } \\
\text { escovar os dentes e } \\
\text { bochechar) }\end{array}$} \\
\hline Dormir & & & & \\
\hline \multicolumn{5}{|l|}{$\begin{array}{l}\text { Manter o seu estado } \\
\text { emocional } \\
\text { (humor) sem se irritar } \\
\text { ou estressar }\end{array}$} \\
\hline \multicolumn{5}{|l|}{$\begin{array}{l}\text { Sorrir, rir e mostrar os } \\
\text { dentes sem sentir } \\
\text { vergonha }\end{array}$} \\
\hline $\begin{array}{l}\text { Fazer as tarefas da } \\
\text { escola (ex. ir à } \\
\text { escola, aprender em } \\
\text { sala de aula, fazer o } \\
\text { dever de casa) }\end{array}$ & & & & \\
\hline $\begin{array}{l}\text { Ter contato com as } \\
\text { pessoas (ex. sair com } \\
\text { amigos, ir à casa de } \\
\text { um amigo) }\end{array}$ & & & & \\
\hline
\end{tabular}




\section{OIDP-Infantil: Instruções para a entrevista}

1a Etapa: Identificar os problemas bucais percebidos pelas crianças

A entrevista começa com a Folha 1, Marcar com um $\mathrm{X}$ o(s) problema(s) que a criança tem ou teve nos últimos 3 (três) meses (dar uma referência dizendo "desde o mês de Agosto").

2a Etapa: Avaliação dos impactos bucais na qualidade de vida das crianças

A entrevista individual conta com o auxílio de uma lista completa dos problemas bucais (Folha 1) e a escala analógica e facial (Quadro 1). As respostas serão anotadas no Formulário de Registro OIDP-Infantil (Folha 2). Nos últimos três meses, algum destes problemas (Folha 1), causou dificuldade para ? (LER CADA ATIVIDADE NO FORMULÁRIO DE REGISTRO - FOLHA 2)

Faça a pergunta para cada atividade. Se para uma atividade a resposta for NÃO, então marque 0 (ZERO) tanto para gravidade como também para a freqüência e passe para a próxima atividade. Se a resposta for SIM, leia as Perguntas: a) Gravidade, b) Freqüência e c) Problemas Percebidos, para cada atividade.

Pergunta a) Gravidade: Vou fazer algumas perguntas sobre a gravidade desta dificuldade quando ela aconteceu. Observe a escala abaixo de 1 a 3 . A gravidade da dificuldade aumenta da esquerda para a direita da escala. A figura 1 representa pequena dificuldade, a figura 2 representa média dificuldade e a figura 3 representa grande dificuldade (Usar a escala do quadro 1).

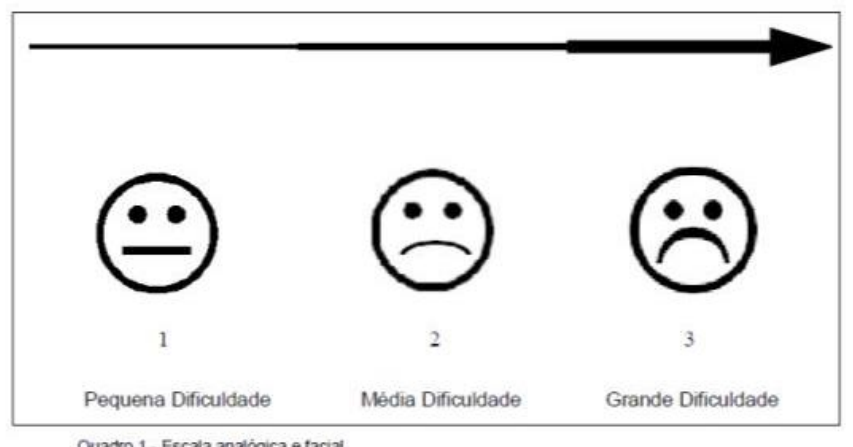

Pergunta b) Freqüência: Aconteceu uma ou mais vezes por mês ou menos de uma vez por mês?

1- Se aconteceu uma ou mais vezes por mês, siga para a Pergunta b1

2- Se aconteceu menos de uma vez por mês, siga para a Pergunta b2

\begin{tabular}{|lr|}
\hline Pergunta b1) Se aconteceu uma ou mais vezes \\
por mês: & 1 \\
- Uma ou duas vezes por mês & 2 \\
- Très ou mais vezes ao mês ou uma ou duas \\
vezes por semana. \\
- Três ou mais vezes por semana
\end{tabular}

\begin{tabular}{|l|}
\hline Pergunta b2) Se a dificuldade \\
aconteceu menos de uma vez por mês, \\
por quantos dias aconteceu no total? \\
- 1 a 7 dias \\
- 8 a 15 dias \\
- mais do que 15 dias \\
\hline
\end{tabular}

c) Problemas Percebidos: Nesse momento a criança deve ter a Folha 1 em mãos e cada atividade do Formulário de Registro deve ser lida e relacionada com os problemas marcados. Escreva na coluna "Problema(s)" o(s) código(s) do(s) problema(s) assinalado(s) pela criança na Folha 1, que tenha(m) afetado a "Atividade" da linha correspondente. 

